\title{
Spacesuit Radiation Shield Design Methods
}

\author{
J.W. Wilson, B.M. Anderson \\ NASA Langley Research Center, Hampton, VA 23681 \\ F.A. Cucinotta \\ NASA Johnson Space Center, Houston, TX 77058 \\ J. Ware \\ ILC Dover, Frederica, DE 19946 \\ C.J. Zeitlin \\ DOE Lawrence Berkeley National Laboratory, Berkeley, CA 94720
}

\begin{abstract}
Meeting radiation protection requirements during EVA is predominantly an operational issue with some potential considerations for temporary shelter. The issue of spacesuit shielding is mainly guided by the potential of accidental exposure when operational and temporary shelter considerations fail to maintain exposures within operational limits. In this case, very high exposure levels are possible which could result in observable health effects and even be life threatening. Under these assumptions, potential spacesuit radiation exposures have been studied using known historical solar particle events to gain insight on the usefulness of modification of spacesuit design in which the control of skin exposure is a critical design issue and reduction of blood forming organ exposure is desirable. Transition to a new spacesuit design including soft upper-torso and reconfigured life support hardware gives an opportunity to optimize the next generation spacesuit for reduced potential health effects during an accidental exposure.
\end{abstract}

\section{INTRODUCTION}

Protecting humans from the adverse effects of ionizing radiation concerns two separate issues: deterministic effects for which severity is related to the level of exposure and stochastic effects for which the probability of occurrence (and not severity) is related to the level of exposure. While any exposure level will surely add to the probability of stochastic effects such as cancer induction in later life and possibly limit the astronaut's career, it is the potential for deterministic effects occurring soon after the exposure to a large solar particle event resulting in severe health effects impacting mission safety which is of greatest concern during EVA. These health effects and exposure levels are well known from past studies and briefly reviewed in Table 1. Blood count changes can be detected in a population at the lowest levels ( 0.15 to $0.25 \mathrm{~Gy}$ ) but have no noticeable effect within the normal variation of an individual. Increasing levels of severity are seen in the table as the exposures increase. As these effects are seen in the first thirty days of exposure, the National Council on Radiation Protection (NCRP) has recommended 30-day exposure limits to specific tissues related to this early radiation syndrome (NCRP 2000) ${ }^{1}$. In this paper, we are concerned with accidental exposures outside the bounds of normal radiation protection practice wherein the health effects in Table 1 are a possibility.

Table 1. Exposure levels at which adverse effects appear in a normal healthy adult (single, high dose-rate exposures).

\begin{tabular}{|l|c|}
\hline Health Effect & Dose of X or $\boldsymbol{\gamma}$ rays, Gy \\
\hline $\begin{array}{l}\text { Blood count changes in a } \\
\text { population }\end{array}$ & $0.15-0.25$ \\
\hline $\begin{array}{l}\text { Blood count changes in an } \\
\text { individual }\end{array}$ & 0.5 \\
\hline Vomiting "effective threshold" & 1.0 \\
\hline Mortality "effective threshold" & 1.5 \\
\hline $\begin{array}{l}\text { LD50, } \\
\text { minimal supportive care }\end{array}$ & $3.2-3.6$ \\
\hline $\begin{array}{l}\text { LD50, } \\
\text { supportive medical treatment }\end{array}$ & $4.8-5.4$ \\
\hline Erythema threshold & 6.0 \\
\hline Moist desquamation & 30.0 \\
\hline
\end{tabular}


System design and operational requirements are set to prevent deleterious deterministic effects and limiting the risk of stochastic effects by applying exposure limits similar to those for low-Earth orbit established by the NCRP $(2000)^{1}$ and implementing an operational safety program analogous to that recommended for low-Earth orbital operations (NCRP 2002) ${ }^{2}$. Specific implementation depends on operational and engineering design criteria derived from the above exposure limitation requirements and environmental knowledge based on past observations. Beyond these design and operational considerations is the probability or possibility that exposures exceed the planned limitations and the related severity of biological effects are greater than expected since normal design and operational capability have possibly failed.

In this case, "contingency operational plans" for evaluation of medical status of the exposed astronaut and provisions for useful medical practice are required to adequately treat an injured astronaut during the mission. Additionally, one should pursue the evaluation of spacesuit parameters to reduce exposures to critical tissues and thus enhancing astronaut health status under such accidental exposure scenarios. In the present paper, we will provide insight into spacesuit design processes under such exceptional exposure conditions and outline methods to enhance astronaut survivability under accidental exposure conditions.

\section{SPACESUIT DESIGN CONSIDERATIONS}

The NCRP recommendations on critical organ exposure limitation in low-Earth orbital operations are chosen to prevent deterministic effects. The 30-day exposure limits appropriate for limiting early somatic syndrome from a solar particle event (SPE) are given in Table 2. These limits are likely to remain unchanged for lunar operations. As a practical matter, Gy-Eq (dose weighted by radiobiological effectiveness, RBE) from proton exposures is approximately given by the dose equivalent (dose weighted by $\langle$ Quality factor $>\approx 1.5 \equiv$ proton $\mathrm{RBE}$ ) as shown by Wilson et al. (2002) ${ }^{3}$. It is clear that maintaining exposures to within these limits during EVA depends on operational procedures and possible temporary shielding being provided during the sortie. Most EVA protection studies have concentrated on such operational and temporary shielding considerations (Simonsen et al. $1993^{4}$, Ross et al. $1997^{5}$, Kim et al. $1999^{6}$, Wilson et al. $1999^{7}$, Reames $1999^{8}$, Neal and Townsend $2005^{9}$ ).

Table 2. Organ exposure constraints (Gy-Eq) to prevent early somatic effects (NCRP 2000).

\begin{tabular}{|l|c|c|c|}
\hline Critical organ & $\begin{array}{c}\text { Blood forming } \\
\text { organ (BFO) }\end{array}$ & Skin & Ocular lens \\
\hline 30-day limit & 0.25 & 1.5 & 1.0 \\
\hline
\end{tabular}

In many of these prior studies, little attention was given to the degree of protection provided by the spacesuit since radiation protection was mainly considered to be an operational and temporary shelter issue and spacesuit parameters were chosen for isolating nonradiation related environmental factors. We start this present study by providing a comprehensive overview of the EVA protection problem.

\section{EVA AND SOLAR PARTICLE EVENTS}

To survey the issues relative to human exposure during EVA, we have generally used simplified shield models of equivalent aluminum as the shield distribution of a modern exploration spacesuit is not yet defined. The spacesuit fabric is represented by $0.3 \mathrm{~g} / \mathrm{cm}^{2}$, the helmet by $1 \mathrm{~g} / \mathrm{cm}^{2}$, and the backpack by $5 \mathrm{~g} / \mathrm{cm}^{2}$. In seeking shelter, a rover pressure vessel is taken as $1 \mathrm{~g} / \mathrm{cm}^{2}$, a typical equipment room is $5 \mathrm{~g} / \mathrm{cm}^{2}$ and a specific storm shelter as $10 \mathrm{~g} / \mathrm{cm}^{2}$. The representation of human geometry with the distributed organ tissues is especially important and our studies use the Computerized

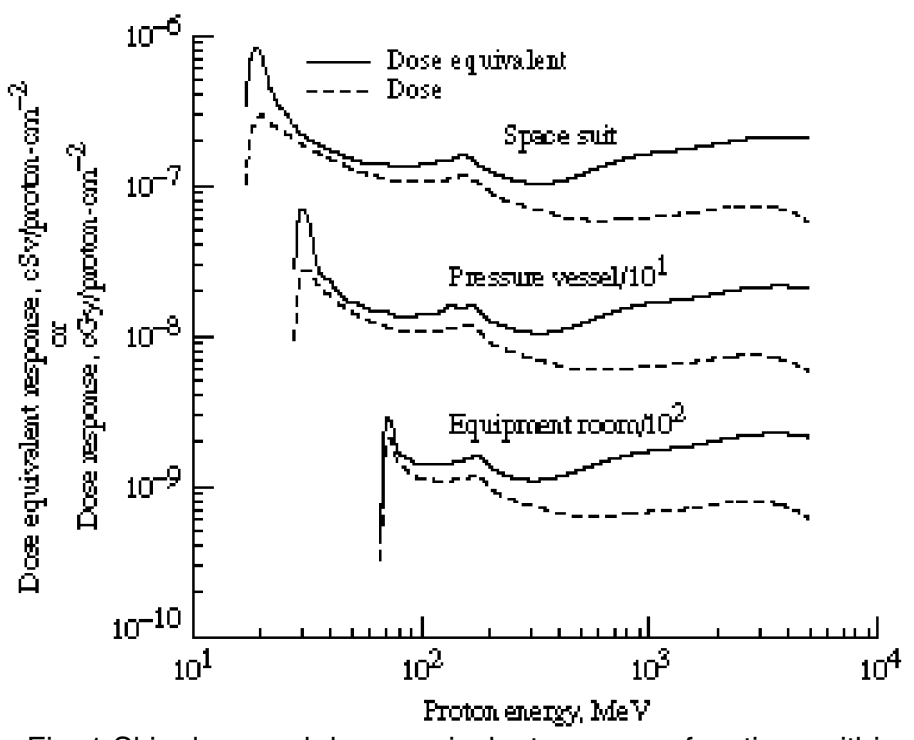

Fig. 1 Skin dose and dose equivalent response functions within typical shield configurations.

Anatomical Man (CAM) model representing the 50 percentile Air Force pilot. Although anisotropies of the SPE environment occur in the early minutes of the event, isotropy is quickly reached in the event and is assumed herein from the event onset.

Dose and dose equivalent response functions have been evaluated in the above simplified shield configurations for the skin and blood forming organ (BFO) as shown in Figs. 1 and 2. The tissue dose is related to the response function $\mathrm{R}_{\text {organ }}(\mathrm{E})$ as an integral over the event differential fluence spectra $\Phi(E)$ as

$$
D_{\text {organ }}=\int R_{\text {organ }}(E) \Phi(E) d E
$$


Note the curves for successive shield configurations have been scaled by factors of 10 to clearly separate these curves. The dose or dose equivalent for the event occurs above $\approx 20 \mathrm{MeV}$ in the spacesuit and the proton event fluence greater than $20 \mathrm{MeV}$ is an important factor

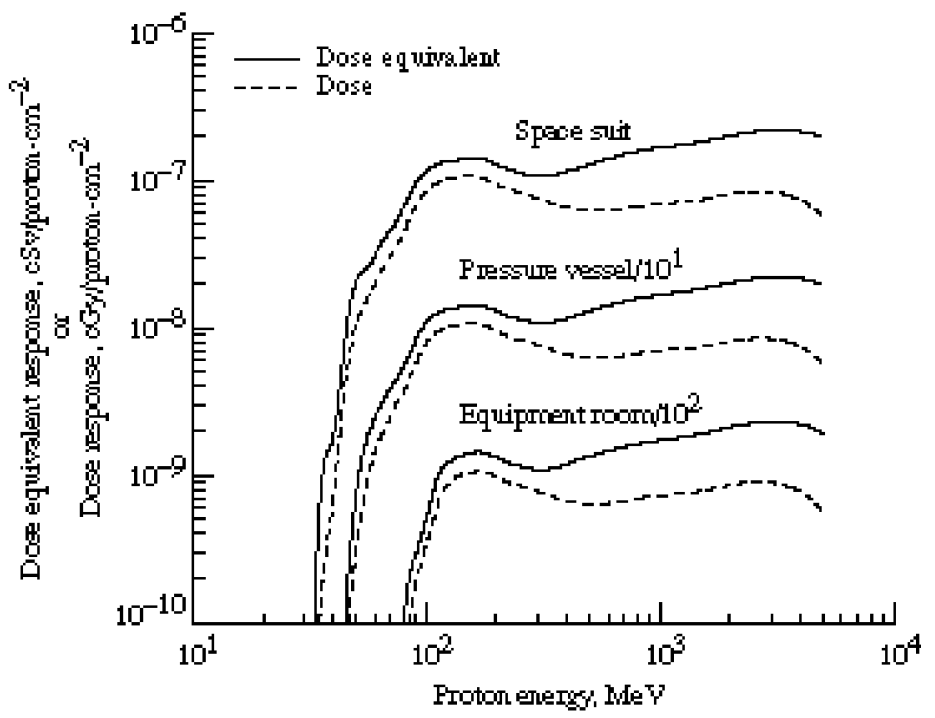

Fig. 2 BFO dose and dose equivalent response functions within typical shield configurations.

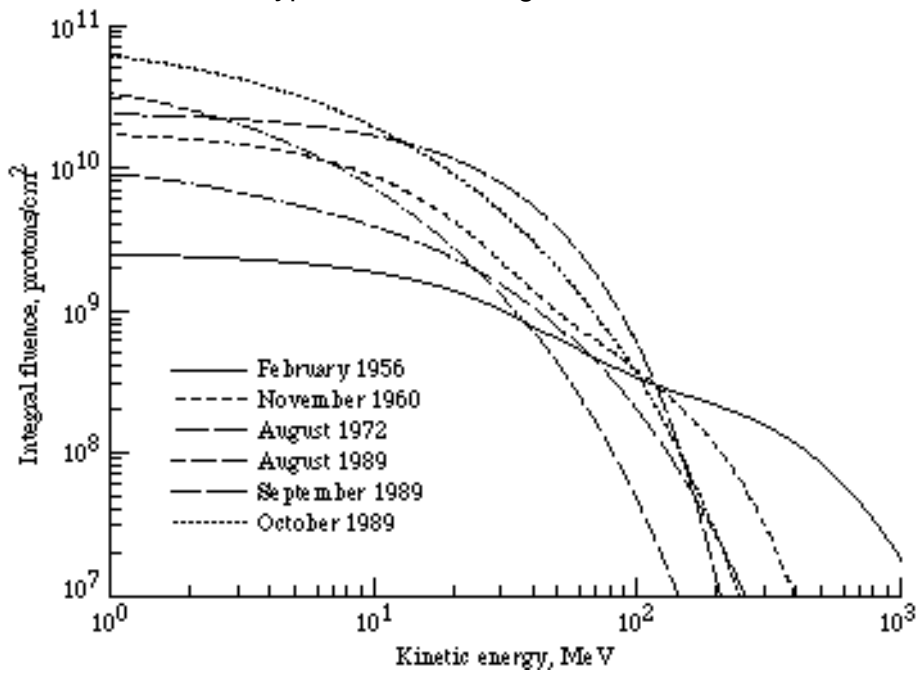

Fig. 3. Large solar proton event integral fluence spectra at $1 \mathrm{AU}$.

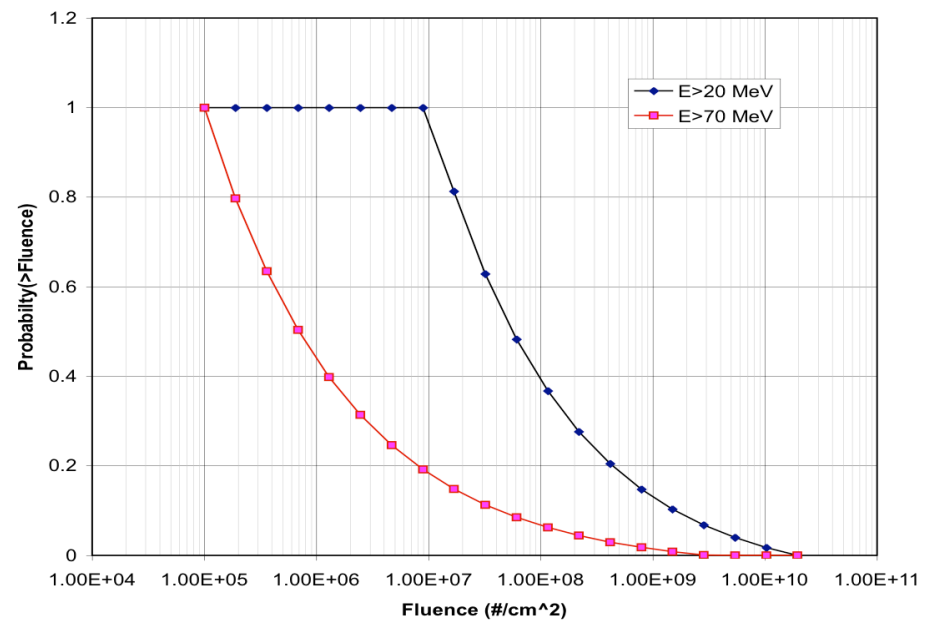

Fig. 4. Probability of a larger single solar particle event fluence of 3 energy greater than $20 \mathrm{MeV}$ and $70 \mathrm{MeV}$. in the exposure. Similarly, the BFO dose is mainly affected by protons above $\approx 70 \mathrm{MeV}$ as seen from Fig. 2 . One may identify critical fluence levels where exposure limits in Table 2 are exceeded as given in Table 3 (Wilson et al. 1999) ${ }^{7}$. It is clear from these response curves that the main effect of shielding is to move the critical energies to higher values with little effect on the critical fluence level.

Table 3. Critical fluence and energy for which organ dose limits in Table 2 are exceeded.

\begin{tabular}{|c|c|c|}
\hline Organ & Fluence, p/cm2 & Energy, MeV \\
\hline BFO & $5 \times 10^{8}$ & $\approx 70$ \\
\hline Skin & $2 \times 10^{8}$ & $\approx 20$ \\
\hline
\end{tabular}

Integral fluence spectra of past large solar particle events of solar cycles 19-22 are shown in Fig. 3. These events exceed the critical fluence levels in Table 3 by orders of magnitude emphasizing the need to avoid such events and that not doing so could threaten the safety of the mission and possibly the life of the astronaut.

Among these historical events, it is clear that the event of 4 August 1972, dominating the fluence between 10 and $150 \mathrm{MeV}$, was among the most dangerous events but occurred between Apollo 16 \&17 causing no harm to the astronaut corp. As a result of its magnitude, this event has been broadly studied. In addition, one may ask for the probability that a given fluence level is exceeded and this answer is given by Xapsos et al. $(1999)^{10}$ based on statistical analysis of historical events. The accumulative event probability distributions are shown in Fig. 4. In the figure is the probability of fluences greater than the two critical energies of $\approx 20$ $\mathrm{MeV}$ and $\approx 70 \mathrm{MeV}$ in Table 3.

It is clear from Fig. 4 that the critical fluence above 20 $\mathrm{MeV}$ for skin exposures is exceeded by 29 percent of the historic solar particle events but only of 2.6 percent of those solar particle events exceed the BFO critical fluence above $70 \mathrm{MeV}$. Adverse health effects that may impact the mission is about four times the critical organ exposure levels in Table 2 as seen by comparing with Table 1. Assuming an astronaut in space responds as a healthy Earthbound adult, the erythema threshold is reached in about 14.6 percent of the events while the effective vomiting threshold is expected for only 0.5 percent of the events. However, the exposed astronaut is subjected to a number of stress related factors and expected health effects are assumed to be elicited at values lower than those in Table 1. On the other hand, the time course of the solar particle events are extended over several hours (and more) and the health effects in Table 1 are expected to occur at somewhat higher values of exposure than those indicated. The extent to which the stress versus exposure protraction will 
counteract is as yet undetermined but is an obvious important design factor and needs better definition using animal exposures with controlled beam exposure experiments and added stress factors. Such health response related design factors are beyond the scope of the present paper and for this study we will take Table 1 at face value.

\section{$\underline{4 \text { August } 1972 \text { SPE and EVA }}$}

Aside from the total fluence, the dose rate is an extremely important parameter. Some somatic threshold doses are observed to double with a factor of ten reduction of dose rate (Langham 1967) ${ }^{11}$. The large events in Fig. 3 lasted for several hours to several days and dose-rate dependent factors are expected to be important. The particle intensities of the August 1972 event are shown in Fig. 5. The temporal behavior is seen to be highly structured and reflects the complicated nature of the multiple sources of this event and the associated interplanetary media (Reames 1999) ${ }^{8}$. Current theory would associate this event with coronal mass ejections (CME) that occur within the disturbed region on the sun. The particle flux is generated in the shock boundary layer of these ejected masses of dense plasma and the relatively undisturbed interplanetary medium. Superimposed on the general structure of particles arriving at $1 \mathrm{AU}$ are short-term increases as the shock boundaries pass the observation point. These local shock events are often limited to acceleration of only low-energy protons as seen in the first shock event for the $>10 \mathrm{MeV}$ flux early in the event (near $69^{\text {th }}$ hour) and effects only the skin dose within a spacesuit. The shock on the trailing edge (near $75^{\text {th }}$ hour) of the main event accelerated the flux at all three energies affecting not only the skin dose but substantial increases of contributions to the BFO exposure. Clearly the dose rates for specific organs can be quite different depending on the energies to which they are most sensitive and the spectral content of the event.

An exponential rigidity spectrum was used to interpolate with continuity at the $30 \mathrm{MeV}$ data point and extrapolation above $60 \mathrm{MeV}$ according to an exponential energy spectrum with e-folding energy of $26.5 \mathrm{MeV}$. The resultant data is used to evaluate the particle spectra at specific tissue sites using the BRYNTRN code (Wilson et al. 1989) ${ }^{12}$. The protons are transported through the shield and the astronauts body to the tissue point with the atomic and nuclear processes represented.

The dose and dose equivalent rates in the skin and BFO are shown in Fig. 6 . The radiation quality at the skin is variable throughout the event within the spacesuit. The radiation quality within the BFO (a generally deep organ within the body) depends less on both shielding and time. The dose and dose equivalent rates for the skin can be high (1 to 10 Gy or Sv per hour) in a spacesuit. The BFO exposures are about a factor of ten or more

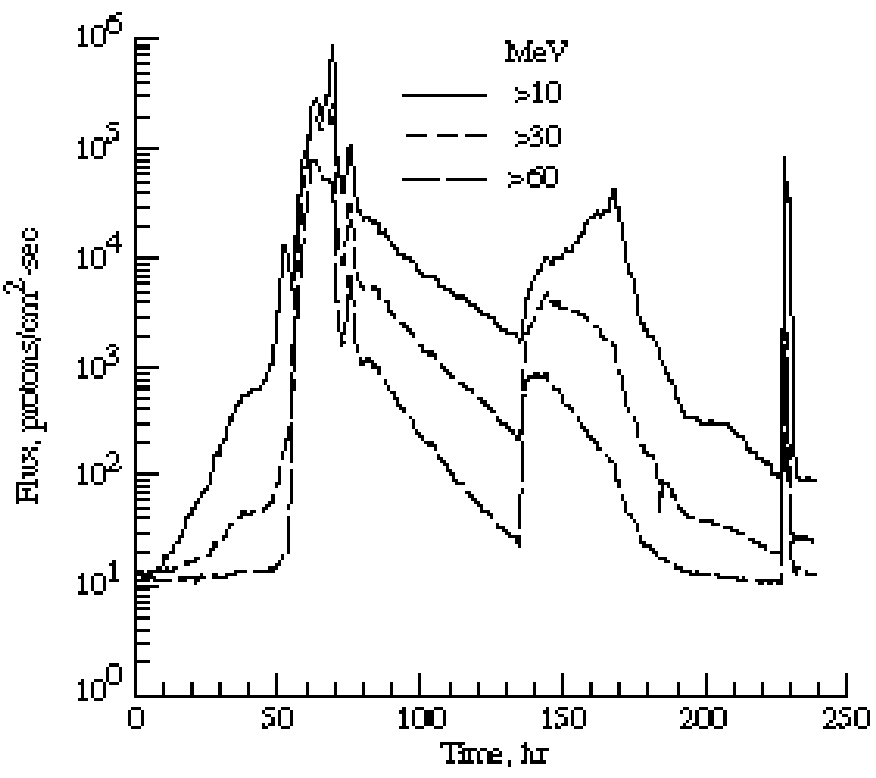

Fig. 5. Measured intensities at $1 \mathrm{AU}$ of the 2-11 August 1972

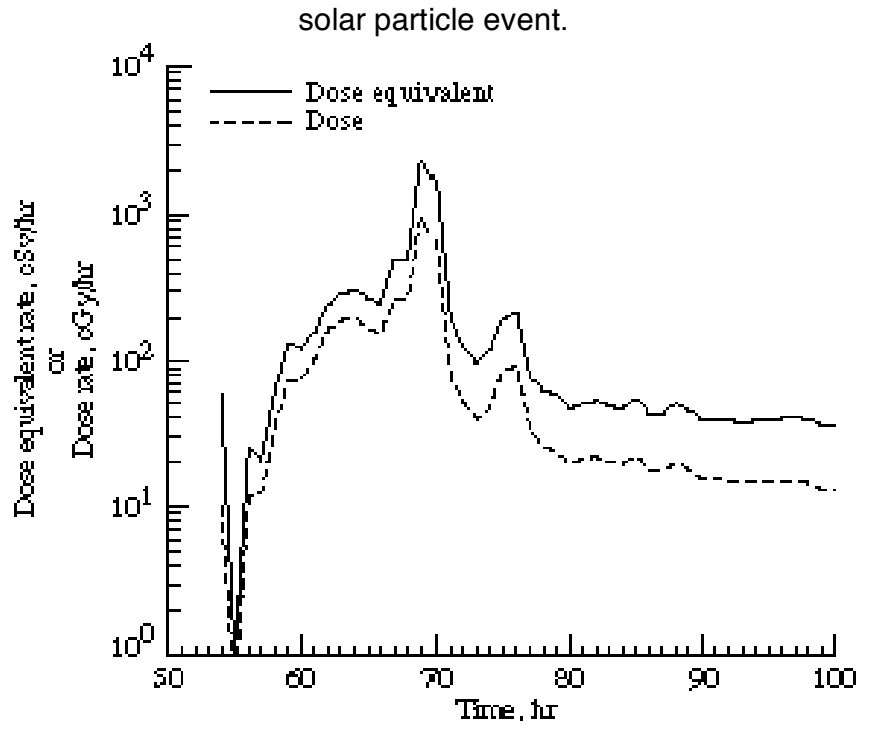

a. Skin

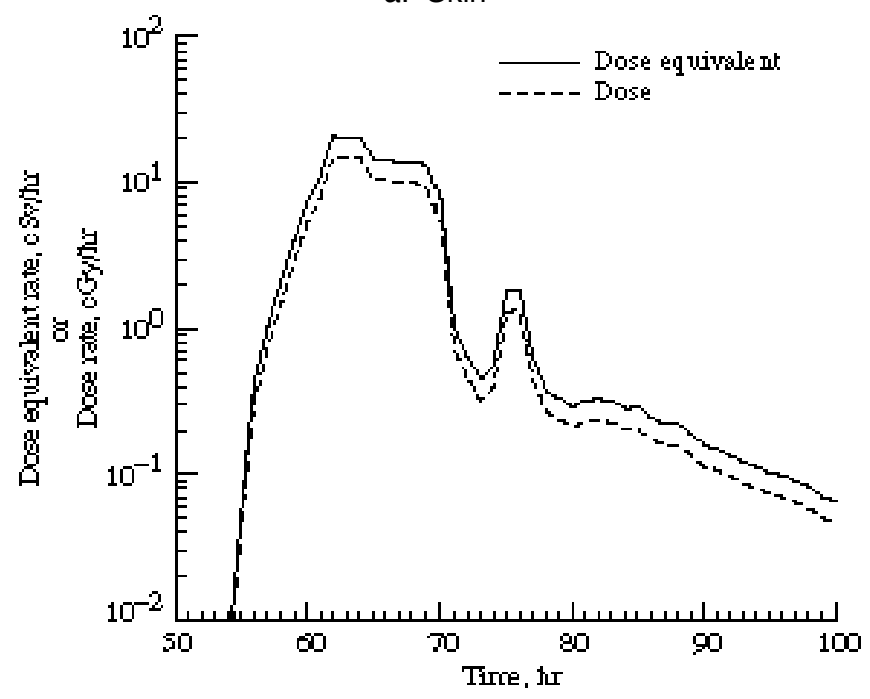

b. BFO

Fig. 6. Calculated (a) skin and (b) BFO dose and dose equivalent rates inferred for the August 1972 solar event within a spacesuit $\left(0.3 \mathrm{~g} / \mathrm{cm}^{2}\right)$. 
smaller (10 to 20 cGy or cSv per hour). The total dose and dose equivalent are given for the three critical tissues in Table 4. The provision of a shelter with 10 $\mathrm{g} / \mathrm{cm}^{2}$ of aluminum will provide sufficient shielding to meet the 30-day limits in Table 2. The exposure levels within the equipment room or shelter in Table 4 can be reduced by large factors by replacing much of the aluminum structure with organic materials of the same total mass as seen in comparing with values within parenthesis in Table 4. Exposures on the lunar surface would be about half of the values in the table as the lunar surface is shielded below the horizon providing a shadow shield over half of the solid angle.

Table 4. Dose equivalent in critical body organs within an aluminum (or polyethylene)* shielding structure during the August 1972 solar particle event, cSv.

\begin{tabular}{|c|c|c|c|c|}
\hline Organ & Spacesuit* & $\begin{array}{c}\text { Pressure } \\
\text { vessel }^{*}\end{array}$ & $\begin{array}{c}\text { Equip. } \\
\text { room }^{*}\end{array}$ & Shelter $^{*}$ \\
\hline Skin & $9350(6770)$ & $3560(2510)$ & $427(267)$ & $110(58)$ \\
\hline Lens & $3830(3530)$ & $2140(1810)$ & $367(251)$ & $101(57)$ \\
\hline BFO & $217(212)$ & $180(174)$ & $65(50)$ & $24(16)$ \\
\hline
\end{tabular}

*values in parenthesis are for polyethylene shield

The problem of shield design for protection against such events is complicated by the statistical nature of solar particle event occurrence. One's confidence of not exceeding the August 1972 event fluence level above 30 $\mathrm{MeV}$ on a one-year mission near the next solar maximum is about 97 percent (Feynman 1990) ${ }^{13}$. (Note, high annual fluence levels are usually dominated by the largest event within the year.) To achieve 99.5 percent confidence level above $30 \mathrm{MeV}$, one must assume a fluence level about 4 times the August 1972 event or approximately 10 times the fluence of the October 1989 events. It is difficult to make an exact assignment of ratios since the spectral content of the events are markedly different. We also note that 4 times the August 1972 event is not equivalent to 10 times the October 1989 event even if the fluence levels and spectral content were the same since the time structure of the events is radically different. We suggest that 4 times the August 1972 event be taken as an approximation to the 99.5 percentile annual fluence with the time structure being that most of the particles arrive in a several hour period.

A rationale for shield design may be to design for the largest event observed recognizing that it may be exceeded with 3 percent probability. An event of 4 times the August 1972 event would appear as an accidental exposure not accounted in the design process and one would plan medical procedures as a contingency to cover the possibility of accidental exposure. One can contemplate that the health of the astronaut can be severely impacted in the unlikely occurrence of a 99.5 percentile event as seen in Table 5. Again the added safety provided by using an equal mass of polymer as opposed to aluminum shielding can be important as seen in table 5. Although the design limits in Table 2 would be exceeded even within a shelter made of polyethylene, early radiation syndrome is unlikely as seen from comparing the shelter organ dose equivalent with Table 1 again emphasizing the potential importance of organic materials for radiation shielding to add a safety margin without adding to mission launch costs.

Table 5. Dose equivalent in critical body organs within an aluminum (or polyethylene) ${ }^{\star}$ structure for an event 4 times that of August 1972, Sv.

\begin{tabular}{|c|c|c|c|c|}
\hline Organ & $\begin{array}{c}\text { Space- } \\
\text { suit }^{*}\end{array}$ & $\begin{array}{c}\text { Pressure } \\
\text { vessel }^{*}\end{array}$ & $\begin{array}{c}\text { Equip. } \\
\text { room }^{*}\end{array}$ & Shelter $^{*}$ \\
\hline Skin & $374(271)$ & $142(100)$ & $17(10.7)$ & $4.4(2.3)$ \\
\hline Lens & $153(141)$ & $86(72)$ & $15(10)$ & $4.0(2.3)$ \\
\hline BFO & $8.7(8.5)$ & $7.2(7.0)$ & $2.6(2.0)$ & $1.0(0.6)$ \\
\hline
\end{tabular}

\section{September 1989 SPE and EVA}

The 29 September 1989 solar particle event is the third largest observed at ground leve/ under direct measurement following the 23 February 1956 and 19 November 1949 events but with a well characterized spectrum in both energy and charge distribution. This iron rich event lasted over several hours and has been extensively analyzed in recent years (Kim et al. 1999) ${ }^{6}$. The particle spectra are shown in Fig. 7. A full discussion of the development of these curves and comparison with satellite data is given in Kim et al. (1999) ${ }^{6}$.

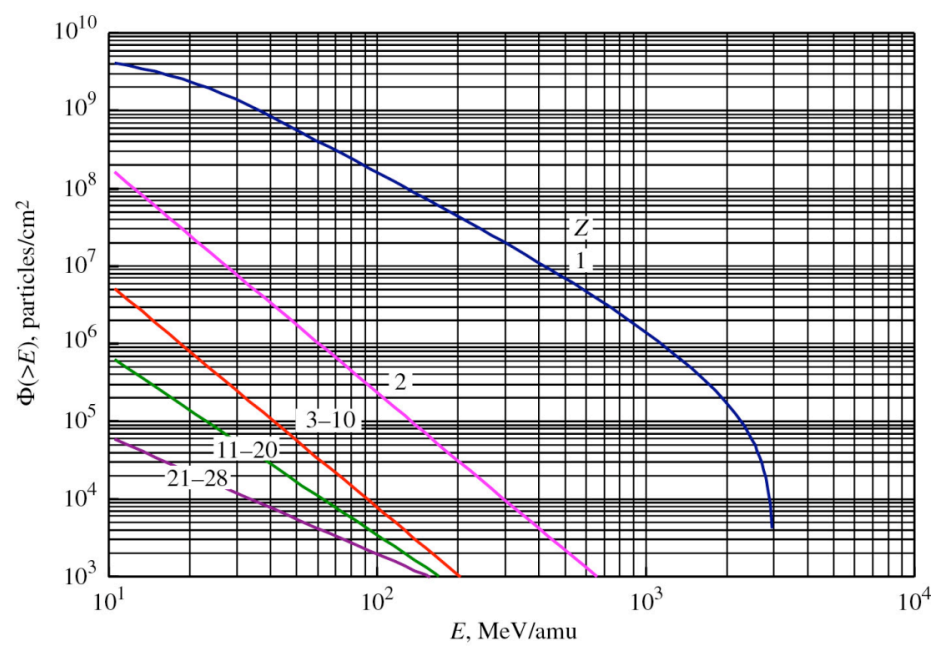

Fig. 7. Analytic approximated multiple charged ion spectra evaluated for the 29 September 1989 solar particle event.

Dose equivalent to the skin and BFO within a spacesuit, a pressure vessel, and an equipment room were calculated using the HZETRN code with results shown in Fig. 8. Charge 1 and 2 ions give comparable contributions to the skin within the spacesuit as seen in Fig. 8a but the ions with higher charge attenuate quickly with additional shielding as seen in the figure. The dose equivalent in the BFO is always dominated by penetrating protons for this deep organ for all shield 
configurations as seen in Fig. 8b. Even so, penetrating helium ions always give significant contributions on the order of 10 percent at the larger penetration depths (beyond $1 \mathrm{~g} / \mathrm{cm}^{2}$ ). The high rate of attenuation of incident ions and especially the helium and heavier ions in the spacesuit fabric provides one means of reducing skin exposures.

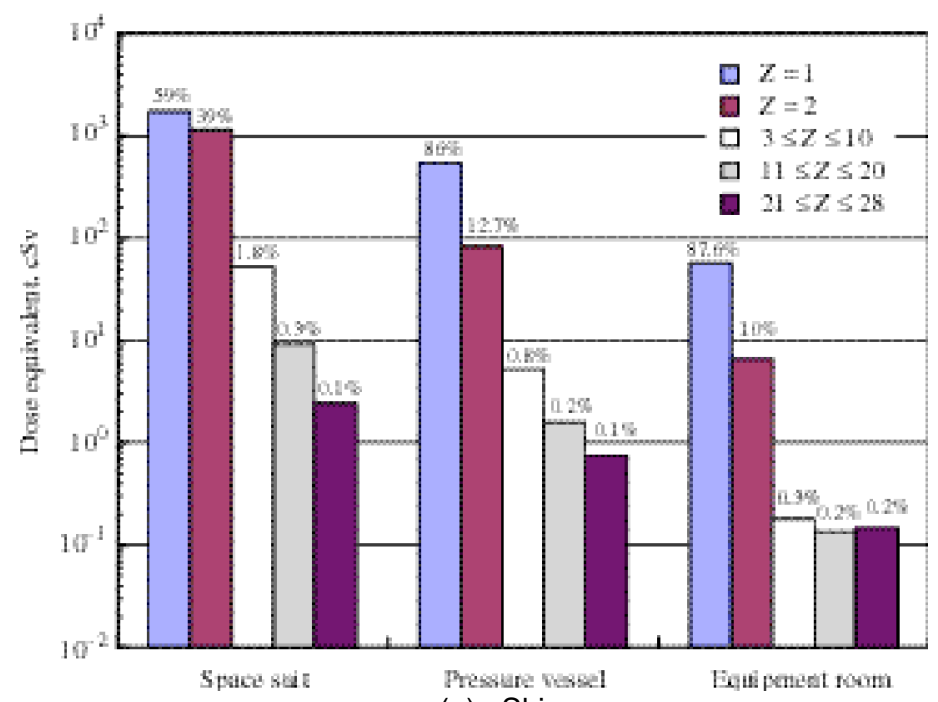

(a) Skin

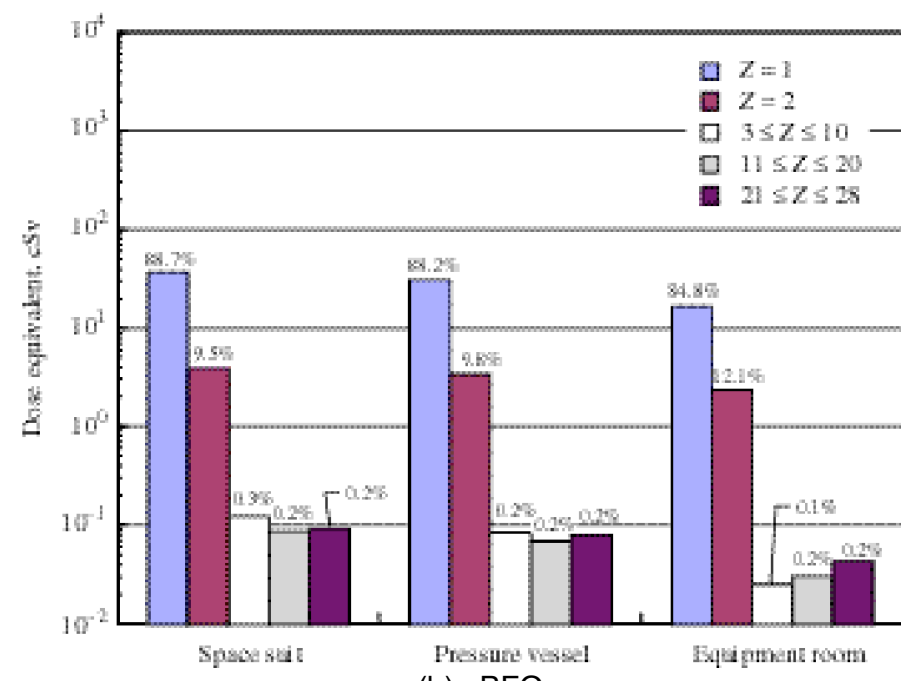

(b) BFO

Fig. 8. Dose equivalent to skin and BFO within a spacesuit, a pressure vessel, and an equipment room during 29 September 1989.

\section{HEALTH EFFECT MODIFYING FACTORS}

The design process would be aimed at keeping exposures within acceptable levels as given by the limits in Table 2. Even so, the nature of space operations requires that work or exploration activity be extended into relatively unprotected regions (e.g., spacesuit or poorly shielded rover) or in living quarters that tend to be an enclosed space surrounded by only a pressure vessel wall. The exposures can be kept at relatively safe levels by a warning to the astronaut to seek shelter in an adequately protected region during a solar particle event. Even so, the occasion may arise that the shelter may not be acquired as planned and the exposures to the astronaut can be very high especially in a spacesuit but even in a pressure vessel as seen in Tables 4 and 5 . Alternatively, the design may be to provide protection against the August 1972 event (Table 4) and an improbable more intense event (Table 5), if it occurs leading to higher than anticipated exposures, would be considered as an accidental exposure. Exposures at which significant health effects occur have been summarized from various sources by the Langham $(1967)^{11}$ and NCRP $(2000)^{1}$ and are shown in Table 1. The dose associated with 50 percent mortality $\left(\mathrm{LD}_{50}\right.$ value) is affected by the degree of medical support and intensive medical care can greatly increase the chances of survival (effectively lowering $L^{2} D_{50}$ ). As discussed below, the $L_{50}$ is also affected by the space related stress factors. Clearly a significant probability of early radiation syndrome could result unless dose rate effects are sufficiently important to reduce the risks.

As an example, the threshold for observable early skin response is about $6 \mathrm{~Sv}$ for prompt exposures (approximately 30 minutes or less). The effects of protraction of the exposure to several hours increases the effective threshold as $\mathrm{T}^{0.29}$ where $\mathrm{T}$ is the exposure duration for an overall correction factor of about 2.15 for the August 1972 event. Even then, the exposures in Table 4 are likely to cause early adverse skin responses even in a pressure vessel. Aside from this crude analysis, we have no detailed models for many tissues as those available for the BFO response developed by the military for field assessment in tactical nuclear warfare (Jones et al. 1994, Jones 1981) ${ }^{14,15}$. There is probably enough data on dose and dose rate effects on skin and crypt cells of the gut to develop a model similar to that available for the BFO.

Recent practical experience was gained as a result of the Chernobyl accident where most exposures were characterized as a relatively uniform whole body dose due to gamma rays and an order of magnitude larger surface exposure from beta emitters (UNSCEAR 1988) ${ }^{16}$ which is somewhat similar to space exposure distributions as shown in Tables 4\&5. There were no deaths among those whose whole body exposure at Chernobyl was less than 2 Gy. All patient exposures of the marrow system with doses greater than 2 Gy were given supportive care including isolation, antibiotics, and in extreme cases transfusions and transplants. Radiation induced skin reaction was a complicating factor in overall treatment UNSCEAR $(1988)^{16}$. Only one death occurred among those exposed between 2-4 Gy under conditions of intense supportive care related to added complications of extreme skin exposure effects.

The diagnostics of the Chernobyl accident relied on biological and physical dosimetry. The blood elements within exposed individuals were monitored within 12 
hours of the accident and taken as an indication of the level of exposure. To understand this methodology, we show the estimated kinetics of the marrow system within the Jones et al. model in Fig. 9. The stromal cells reside on the bone surface and consist of those populations associated with the yellow marrow. The stem cells attach to the stroma and cytokines are transferred through cell-to-cell gap junction channels during hematopoiesis, however stem cells are highly mobile inside the body and circulate in the blood to other, perhaps depleted sites of the marrow thus aiding survival (Wilson et al. 1999) ${ }^{7}$. The stroma cells provide

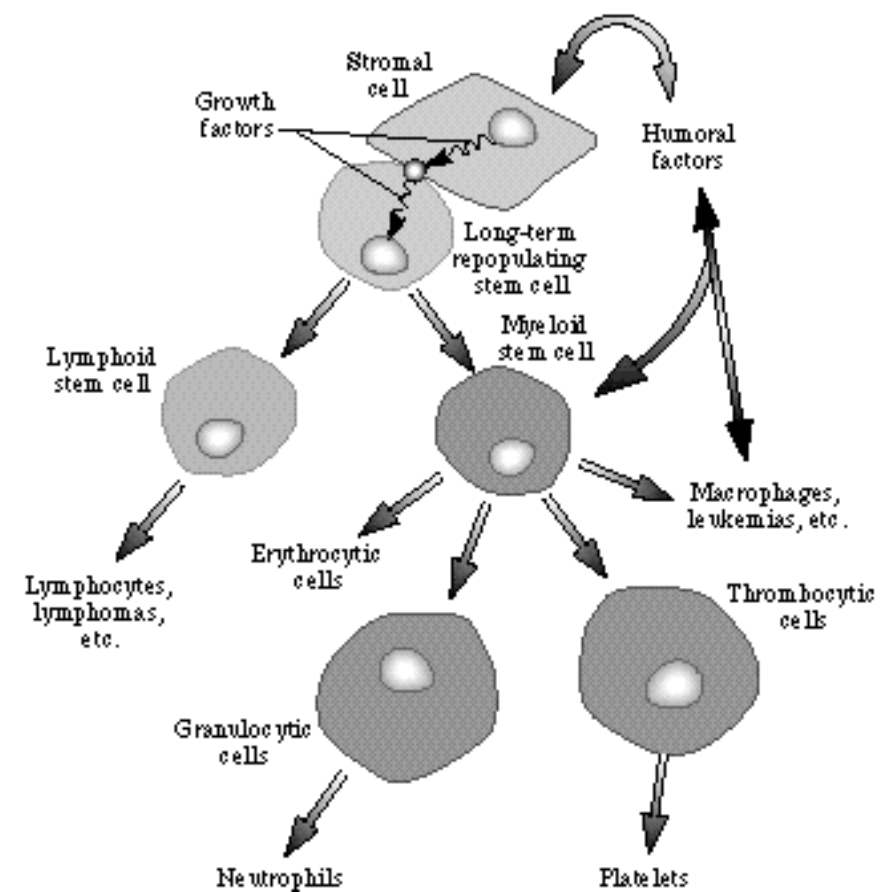

Fig. 9. Cell populations and humor factors controlling the peripheral blood elements.

growth factors that are responsible for the rate of cell propagation among the various stem populations. The long term repopulating stem cells differentiate into lymphoid and myeloid stem populations that further propagate into specific blood elements. Humoral factors added by the stromal cells control the rate of progression of these differentiated stem populations. All other blood elements are produced by further differentiation among these two stem populations. Radiation injury to these stem and stromal populations will have its ultimate consequences in the peripheral blood. The time-course of these peripheral blood elements (specifically the lymphocytes, neutrophils, and platelets) were used to estimate the level of exposure (UNSCEAR 1988) ${ }^{16}$. Kinetic models of the human stem and stromal populations based on animal studies are used in the present report to development a better understanding of the anticipated response of the astronaut to solar particle event exposure.

The human $\mathrm{LD}_{50}$ to marrow seems to be about 3 Gy for the atomic bomb survivors (Levin et al. 1992) ${ }^{17}$. But the $\mathrm{LD}_{50}$ for man can be increased with antibiotics, blood transfusions, and cytokine therapy to about 6 Gy. Intensive medical care including bone marrow or blood stem cell transplant could increase survivability to high levels as shown in Table 1 but such medical procedures themselves carry additional attendant risks (UNSCEAR $1988)^{16}$ that may be modified by pre-conditioning to the space environments. Conversely, Morris, Jones and coworkers $(1988,1997,1999)^{18-20}$ have modeled 13 species of test animals and predicted the $\mathrm{LD}_{50}$ for man to be only about $1.8 \mathrm{~Gy}$ if confined in a cage under nonsterile conditions similar to that used for test animals. Such shifts may in fact be typical for space exposure and would be an important determinant of astronaut health. The genetic selection of astronauts and their conditioning may increase their radio-resistance but space environmental factors, stress of close confinement, stress from microgravity, cabin atmosphere, skin exposure effects, etc. will likely decrease their radio-resistance.

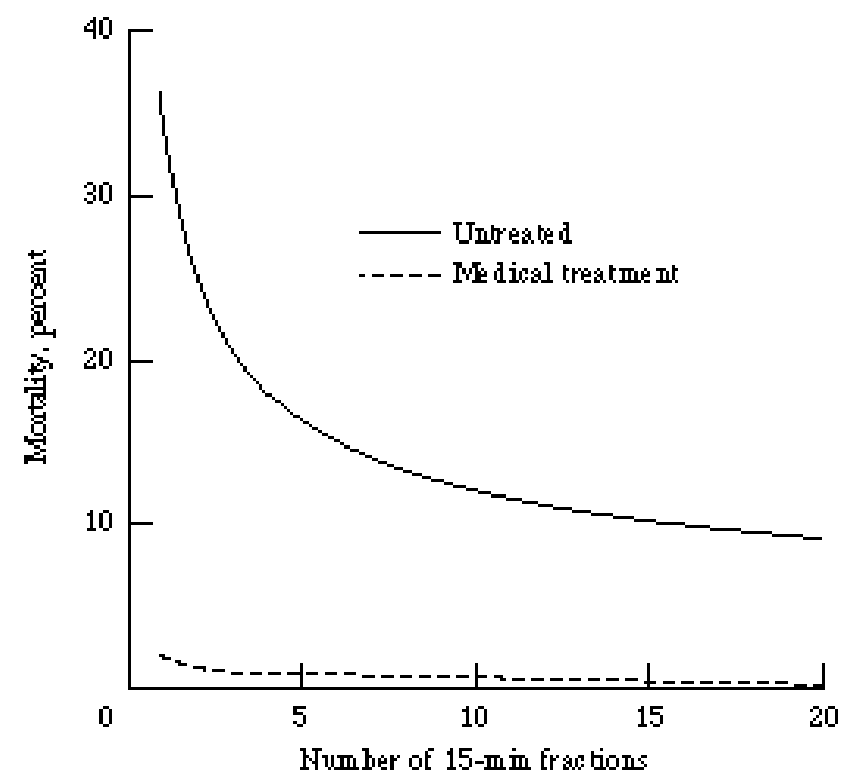

Fig. 10. Mortality for an hourly-fractionated 2 Gy bone marrow dose from $200 \mathrm{kVp} \times$ rays as a function of the number of fractions. The lower curve indicates decreased mortality with supportive medical treatment.

We use the model for early lethality as adapted by Jones et al. $(1981,1994)^{14,15}$ to examine the recovery effects in humans due to rather large BFO exposures. As an example, Fig. 10 shows the probability of death for a 2 Gy dose to the bone marrow by $250 \mathrm{kVp}$ X-rays delivered as multiple equal fractions one hour apart. Each fraction was given in a 15-minute exposure. Probability of death can be quite large when received in a single high dose rate fraction (note, Jones estimates that the bone marrow dose $L_{50}$ of $250 \mathrm{kVp}$ X-rays is 2.15 Gy while that of ${ }^{60} \mathrm{Co}$ gamma-rays is $2.95 \mathrm{~Gy}$ ). It is expected that supportive medical treatment will allow survival as shown in the figure. As the number of fractions is increased, the probability of death drops dramatically to less than 10 percent (even without medical treatment) beyond 15 fractions (or equivalently 15 hours). The stem and stromal cell survival at the end 
of each fractionated exposure is shown in Fig. 11. Stem cell survival for the single 2 Gy marrow dose is very low (much less than ten percent). As the number of fractions is increased the stem cell survival shows a dramatic increase approaching forty percent. Likewise, similar but less dramatic changes in the stromal cell population and recovery reduces the probability of death for the 20 fractions at 2 Gy to ten percent. Clearly, population recovery is effective in reducing the risk when the exposure is highly fractionated with adequate time between fractions. The stem and stromal cell populations during exposure and post 2 Gy marrow dose from $250 \mathrm{kVp}$ X-rays given as 20 fractions is shown in Fig. 12. The recovery period in this case is about two to four weeks. These facts are well known in medical therapy.

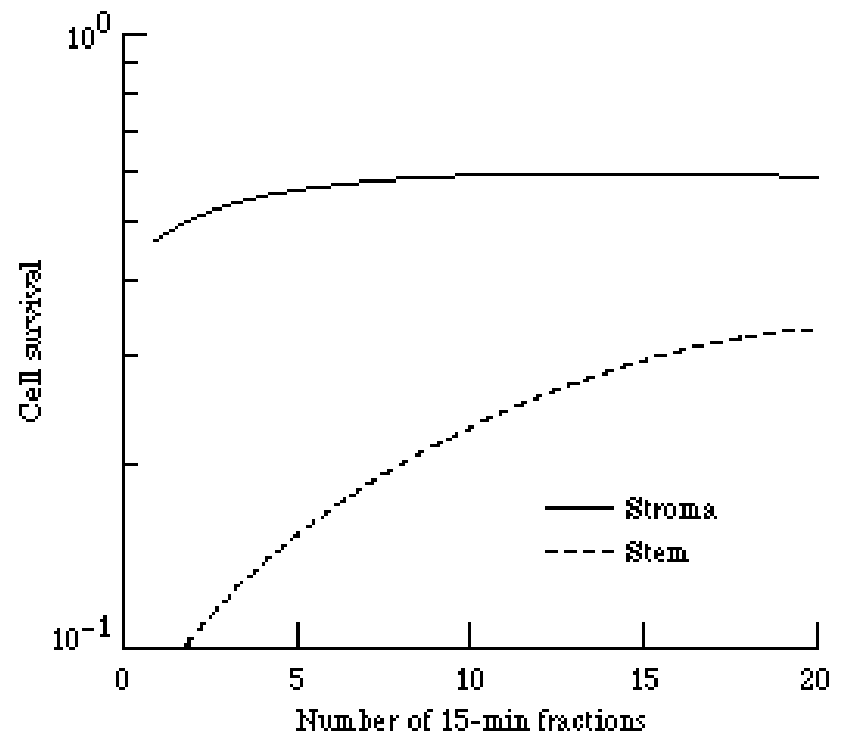

Fig. 11. Stem and stromal cell survival at the end of the exposure period for a fractionated 2 Gy total bone marrow

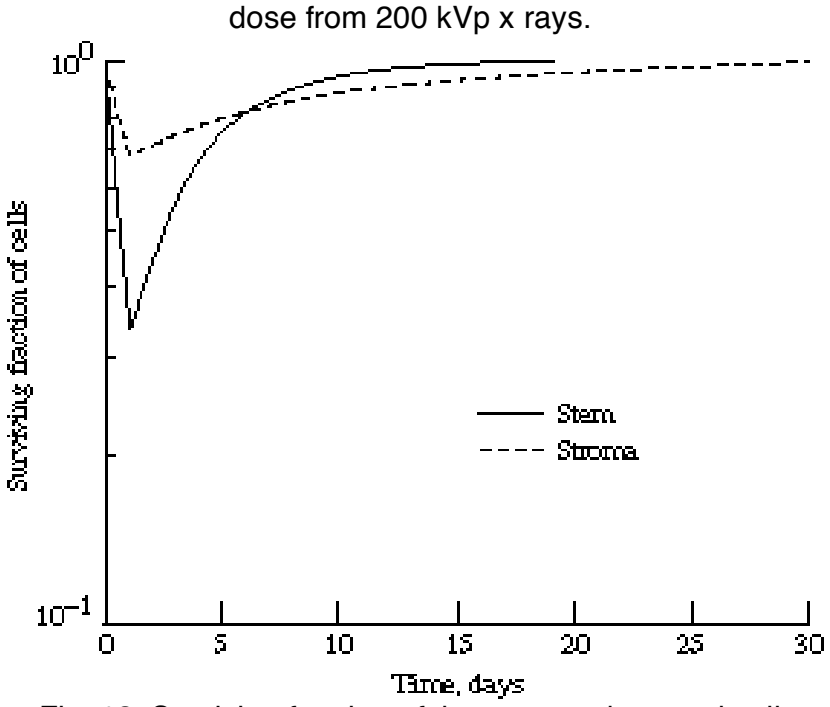

Fig. 12. Surviving fraction of the stem and stromal cell populations for 20 hourly fractions of 2 Gy total bone marrow dose from $200 \mathrm{kVp} x$ rays showing recovery period.

Spacesuit life support systems are limited to eight hours of continuous use. We therefore look at the effects of the worst eight-hour exposure on the biological response. The estimated cell populations shielded by a spacesuit and pressure vessel are shown in Fig. 13 for the August 1972 event. The stem cell population drops to about 58 percent in the spacesuit and 66 percent in the pressure vessel with little risk of death. Of course, responsible protection practice would still require the astronaut to seek shelter to reduce exposures to the levels in Table 2. Assuming an event of a factor two higher flux (approximately a 99 percentile annual fluence level) the worst 8-hour exposures are higher with larger changes in cell populations as shown in Fig. 14. The corresponding risk of death without treatment is 12 and 5 percent, respectively, and medical treatment is likely required. In each case, the effects on the cell populations are slight although the accumulated dose equivalent is large. Note that the higher event flux $(2 \mathrm{x}$ August 1972) is near the $L D_{50}$ but the probability of death (assuming adequate medical treatment and no skin complications) is negligible as a result of dose rate effects and the sparing factor is about a factor of four.

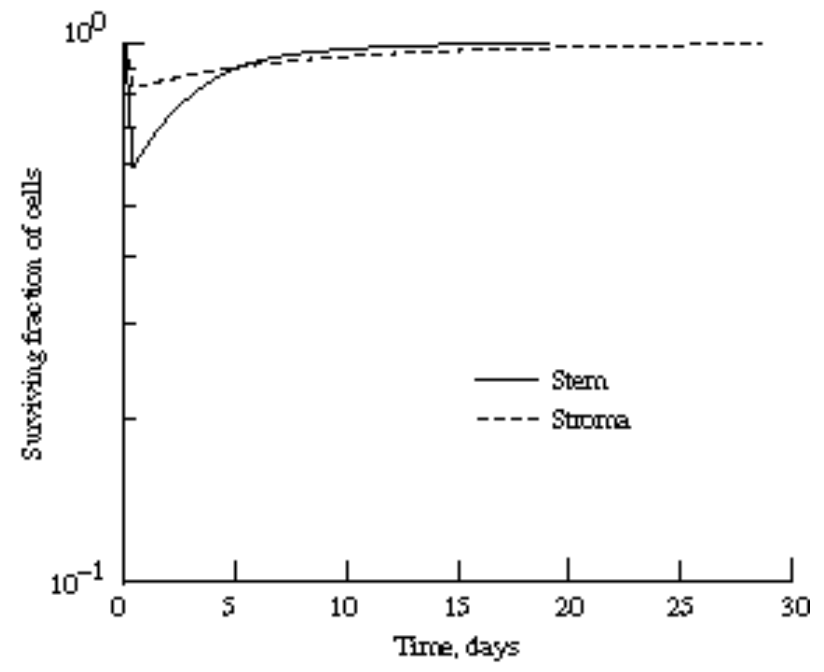

a. space suit

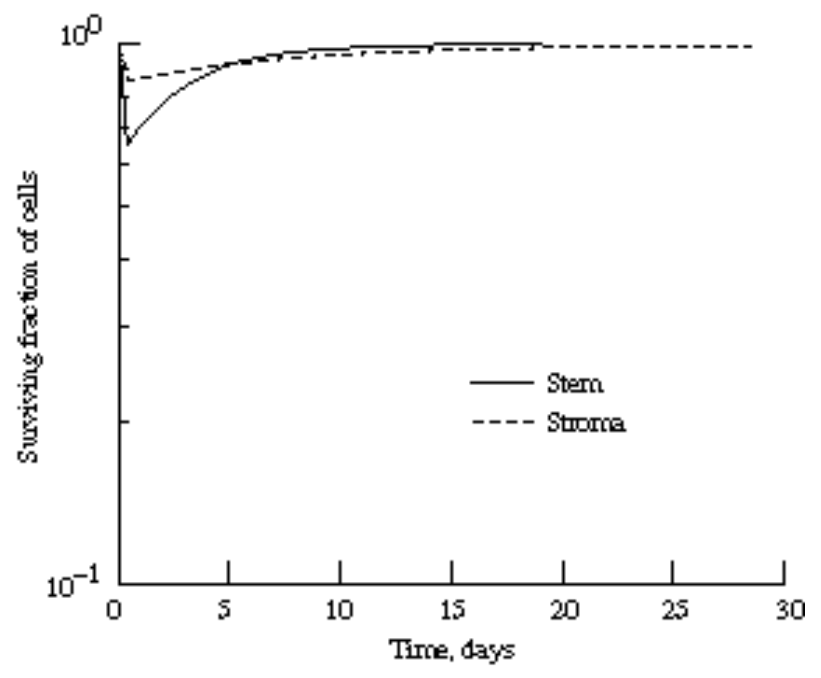

b. pressure vessel

Fig. 13. Surviving fraction of stem and stromal cell populations for eight-hour exposure in (a) spacesuit and (b) pressure vessel for the August 1972 event. 
The August 1972 episode was a sequence of three distinct events over an eight-day period (Fig. 5). The effect of spending the first 50 hours of the event in a pressure vessel or equipment room is shown in Fig. 15. The surviving fraction of stem and stromal cells exhibit repopulation after the passing of the peak of the event so that the latter portion of the event will have little effect on mortality. Indeed, the mortality estimate for the first fifty hours is within 10 percent of the mortality estimate of the worst eight hours. Death is not expected for normal healthy adult exposed to the August 1972 event. If an

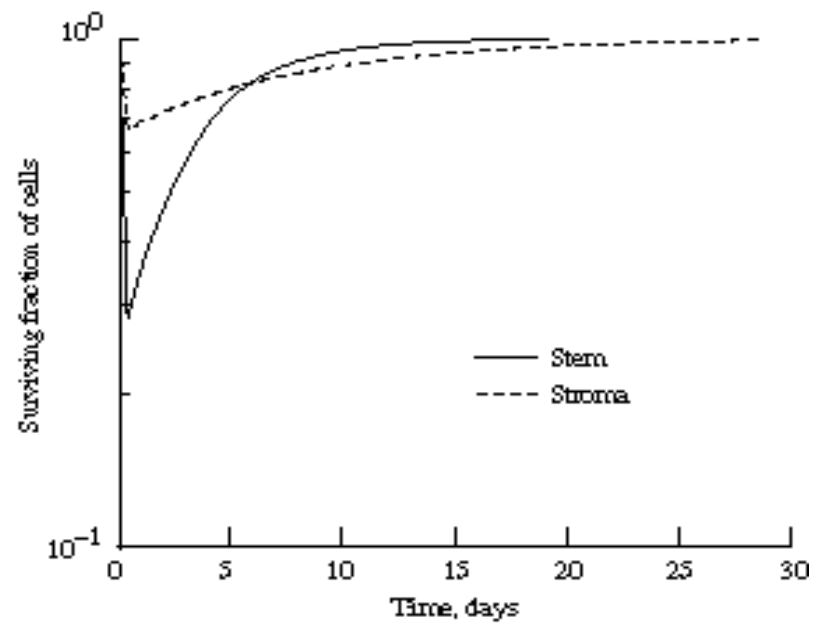

a. space suit

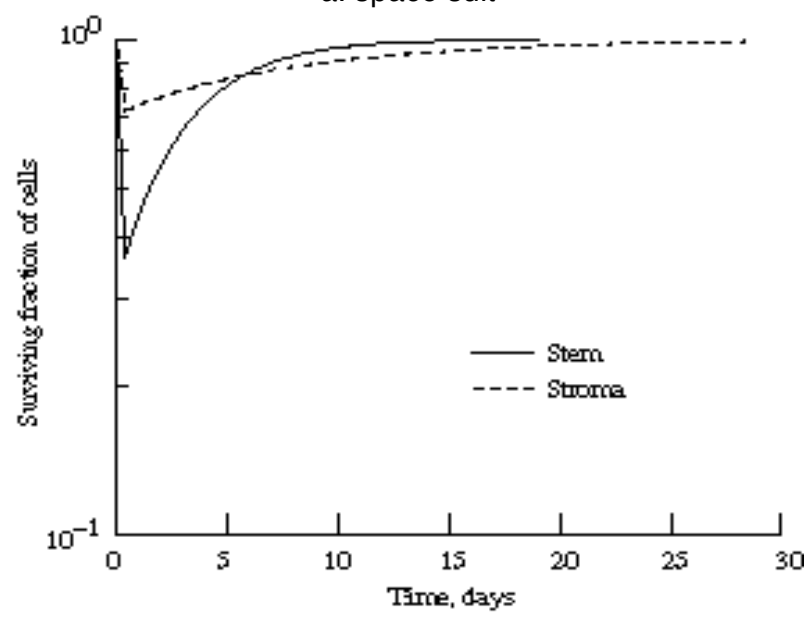

b. pressure vessel

Fig. 14. Surviving fraction of the stem and stromal cell populations for eight-hour exposure in (a) space suit and

(b) pressure vessel for the $2 \times$ August 1972 event.

event twice as large as the August 1972 event occurs (Table 6) then there is a small risk of death without medical treatment (12 percent). Taking the 99.5 percent annual fluence as 4 times the August 1972 event leads to the estimates in Table 6. Depopulation of both stem and stromal cells is severe in the pressure vessel and significant even in an equipment room. The risk of death of a normal healthy adult in the pressure vessel is about 88 percent unless good medical practice is followed in which the risk is reduced to 9 percent. These results are summarized in Table 6 . Again, the use of polymer structures would provide an important safety margin greatly reducing the risks with minimal impact on mission cost. These are extremely improbable events, but if such an event occurs it is apt to have dire consequences in exposure accidents unless adequate planning is made to provide necessary medical support. Within the equipment room, the radiations are greatly reduced and risk of death to a normal healthy adult is small (3 percent) even without medical treatment. Use of polymer materials instead of aluminum would provide an added safety factor to assure survivability for exposures within the equipment room.

Table 6. Expected mortality (percent) of normal healthy adult

\begin{tabular}{|l|c|c|c|c|}
\hline Event & $\begin{array}{c}\text { Space- } \\
\text { suit }\end{array}$ & $\begin{array}{c}\text { Pressure } \\
\text { vessel }\end{array}$ & $\begin{array}{c}\text { Equip. } \\
\text { room }\end{array}$ & Shelter \\
\hline Aug.'72 & $1)^{\star}$ & 1 & 0 & 0 \\
\hline 2xAug.'72 & $12)^{\star}$ & 12 & 0 & 0 \\
\hline 4xAug.'72 & $87)^{\star}$ & 88 & 3 & 0 \\
\hline
\end{tabular}

without adequate medical treatment for various aluminum configurations.

*Worst eight hours ignoring skin complications

In these estimates of mortality, we have not included any increase in radiosensitivity due to space stress factors or the possible complications arising from injury to other

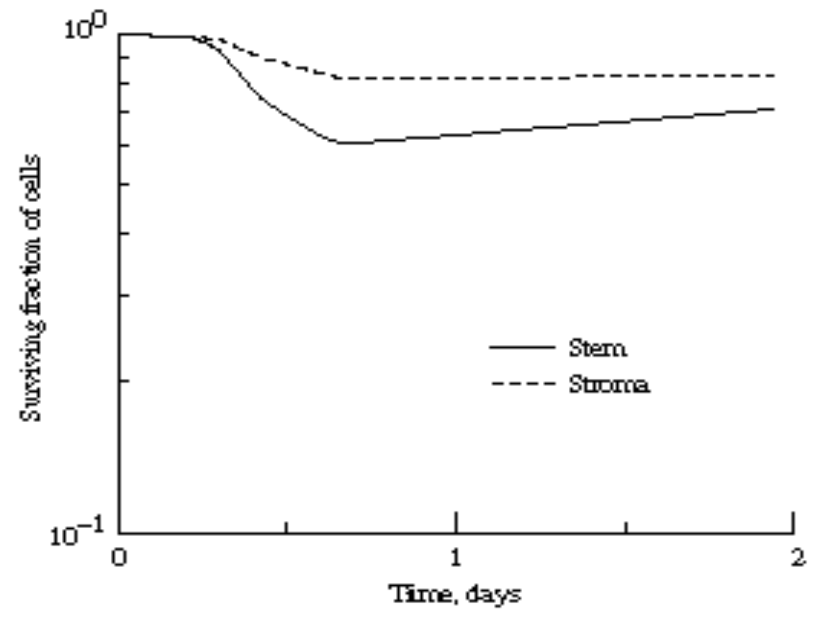

a. pressure vessel

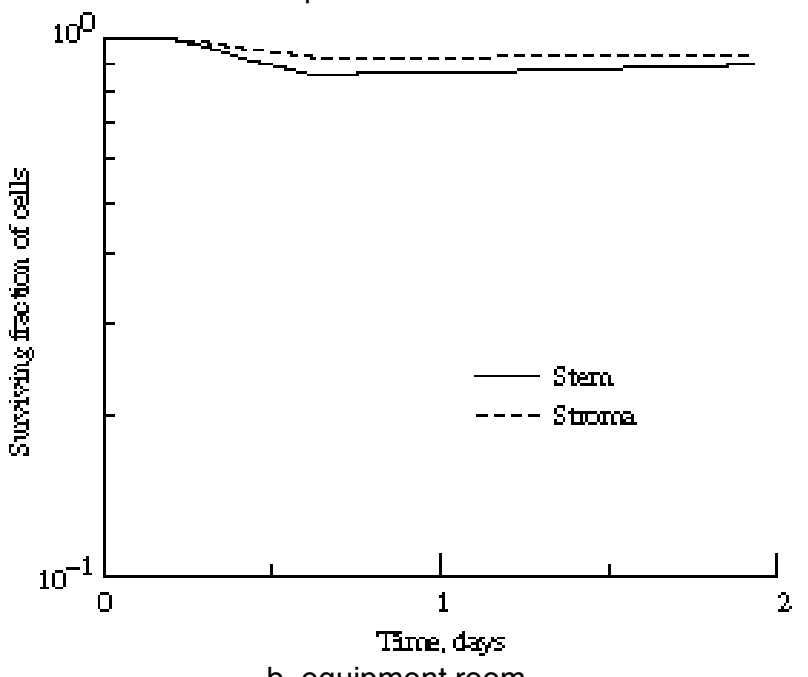

b. equipment room

Figure 15. Surviving fraction of the stem and stromal cell populations for exposure in (a) pressure vessel (a) and 
organs, especially the skin. Even so it appears that astronaut survivability will occur with some medical planning in the case of an accidental exposure except in the improbable case of an event 4 times larger than any observed occurs and the exposures are protracted only over a several hour period. Even then the exposures discussed above are exposure estimates in free space and exposures on the lunar surface are a factor of two lower with a corresponding reduced risk.

\section{SPACESUIT DESIGN PROCESSES}

It is clear from the above discussion that early radiation syndrome for accidental-exposures in a spacesuit involve mainly the sensitive skin and BFO tissues. While it is desirable to keep BFO exposure as low as possible for immune system maintenance, it is essential to provide adequate protection to the skin to prevent medical complications with a depressed immune system. Therefore, two studies were made to examine these issues. A model of the Shuttle spacesuit was developed to examine the sensitivity of BFO exposure to spacesuit parts and a detailed fabric model was developed based on details of the inhomogeneous structure of the fabric sections of the suit including the water filled cooling tubes. A testing program was established to validate the fabric model in proton accelerator measurements.

\section{SPACESUIT MODEL}

The Shuttle spacesuit principal components consist of the Hard Upper Torso (HUT), arm assembly, Lower Torso Assembly (LTA), extravehicular gloves, and helmet. With the Primary Life Support System (PLSS) attached to the back of the suit, the Liquid cooling and the Ventilation Garment (LCVG) is under the pressure suit and against the astronauts body, and the Extravehicular Visor Assembly (EVVA) goes over the helmet. The brief description here is taken largely from (Ross et al 1997) $)^{5}$ and the major components are shown in Fig. 16. The HUT is constructed of fiberglass and covered outside with orthofabric, aluminized Mylar, and neoprene-coated nylon ripstop. The LTA and arm assembly, including the LCVG, consists of orthofabric, aluminized Mylar, neoprene-coated ripstop, polyester, urethane-coated nylon, and water filled cooling tubes. The Extravehicular gloves are similar except they do not include the cooling tubes. The PLSS otherwise known as "the backpack" consists of the primary oxygen system, oxygen ventilation system, liquid transport system, water feed circuit, secondary oxygen pack (SOP), Extravehicular Mobility Unit (EMU) radio, caution and warning system, contaminant control cartridge (CCC), EMU electrical system, EMU battery, and the display and control module (DCM) which is located on the front of the HUT. A listing of these items, their major material constituents, and approximate masses are given in Table 7. The overall dimension of the PLSS unit measures approximately $23 \times 25 \times 7$ inches.

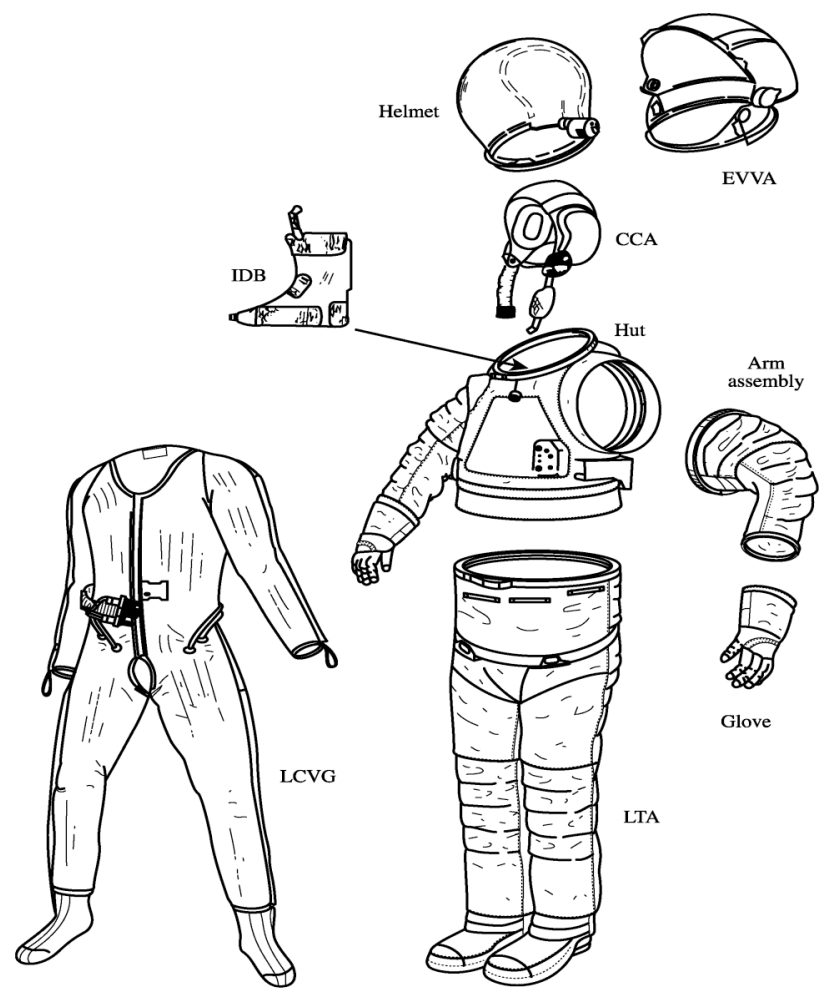

Fig 16. Basic Components of the Shuttle space Suit.

Table 7: Major Material constituents and Approximate Masses of PLSS

\begin{tabular}{|c|c|c|}
\hline Subsystem & $\begin{array}{l}\text { Material } \\
\text { Constituents }\end{array}$ & Mass, kg \\
\hline \multicolumn{3}{|l|}{$\mathrm{O}_{2}$ Ventilating Circuit: } \\
\hline $\begin{array}{l}\text { Regulators, vessels, } \\
\text { fans ... }\end{array}$ & $\mathrm{Fe}, \mathrm{Cr}, \mathrm{Ni}, \mathrm{Cu}, \ldots$ & 14.4 \\
\hline LiOH Assembly & $\mathrm{LiOH}, \mathrm{Fe}$ & 6.4 \\
\hline \multicolumn{3}{|l|}{$\mathrm{H}_{2} \mathrm{O}$ Transport: } \\
\hline $\begin{array}{l}\text { Pump, valves, } \\
\text { sensors }\end{array}$ & $\mathrm{Fe}, \mathrm{Cu}$ & 6.5 \\
\hline Liquid & $\mathrm{H}_{2} \mathrm{O}$ & 4.5 \\
\hline \multicolumn{3}{|l|}{ Electrical System: } \\
\hline Electronics & $\mathrm{Si}, \mathrm{O}, \mathrm{Cu}, \ldots$ & 15.1 \\
\hline Battery & $\mathrm{ZnAgO}$ & 4.5 \\
\hline \multicolumn{3}{|l|}{$\mathrm{O}_{2}$ Purge System: } \\
\hline Bottles & $\mathrm{Fe}, \mathrm{O}_{2}$ & 8.6 \\
\hline Regulator & $\mathrm{Fe}$ & 4.2 \\
\hline
\end{tabular}

Due to the sensitivity of the eyes, the EVVA consists of numerous visors, which have been constructed to provide maximum protection. Most of the visors are constructed of polycarbonate or polysulfone. A list of the different visors and the helmet along with their material composition and areal density is given in Table 8.

For modeling of the suit the commerical CAD software package I-DEAS was used. The effort expended on the modeling of the suit was focused on simplicity but with an accurate representation of those components that contribute most to radiation shielding, i.e. the visors and 
the PLSS. Effort was also spent to make sure that solid angles subtended by the modeled elements were compatible with those of the true suit. The current CAD representation of the space suit assembly is shown in Fig. 17 (Anderson et al. 2001) ${ }^{21}$.

Table 8: Shuttle Space Suit Helmet and EVVA Constituents

\begin{tabular}{|l|l|l|}
\hline Component & Material & $\begin{array}{l}\text { Areal } \\
\text { Density, } \\
\mathrm{g} / \mathrm{cm}^{2}\end{array}$ \\
\hline Outer layer & $\begin{array}{l}\text { Orthofabric- } \\
\text { Teflon/Nomex/Kevlar }\end{array}$ & 0.049 \\
\hline Insulation & Aluminized Mylar -5 plies & 0.014 \\
\hline Spacer & Dacron fiber - 5 plies & 0.011 \\
\hline Inner liner & Teflon & 0.028 \\
\hline EVVA shell & Polycarbonate & 0.381 \\
\hline Sun visor & Polysulfone & 0.190 \\
\hline Eye shade & Polysulfone & 0.190 \\
\hline Protective visor & Polycarbonate & 0.182 \\
\hline Helmet & Polycarbonate & 0.182 \\
\hline
\end{tabular}

Once the solid CAD model of the suit was complete, a finite element model (FEM) was applied to it. This model consists of 28 components representing the different elements of the suit, visors, and PLSS. Due to complexity of model the finite element model has over 30,000 facets. This FEM was then used in the ray tracing procedure to determine the directional shielding at a given target point. Figure 18 shows the FEM of the Shuttle Spacesuit.

The most easily penetrated portion of the spacesuit is covered only by the fabric (Arm assembly and LTA) and the LCVG. This is of greatest importance when the environment contains low energy particles with limited penetration power. Most environmental components contain such particles and are often the most intense component. They are only of concern for tissues that

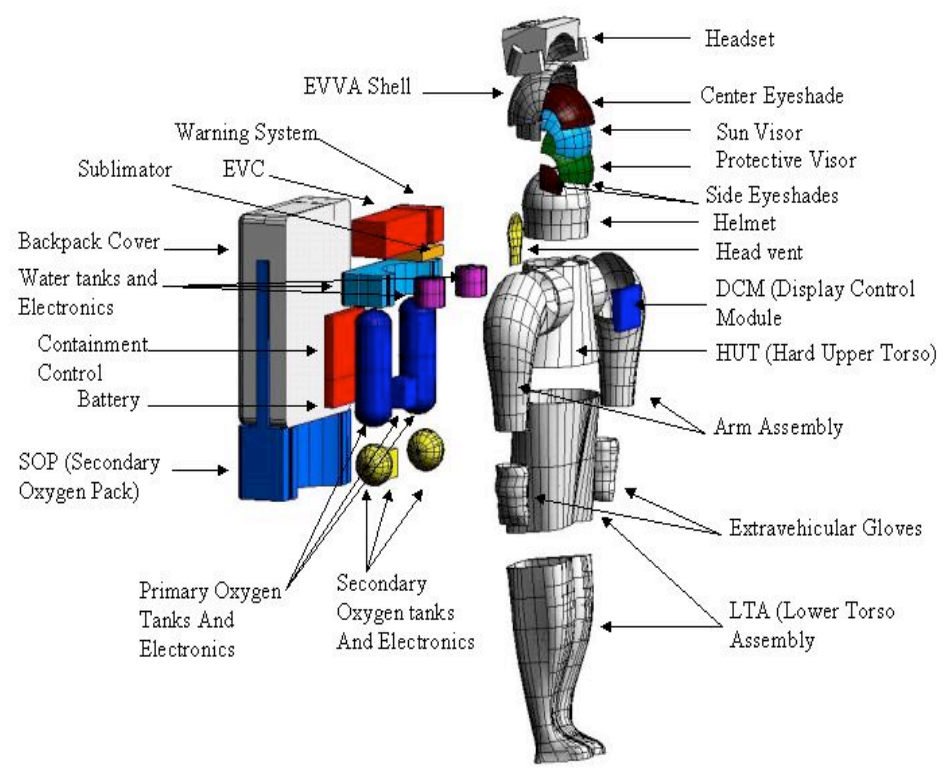

Fig. 17 CAD model of the Shuttle spacesuit. are poorly shielded and not of concern within a space vehicle assembly such as the Shuttle or ISS or for organs deep within the body. The basal layer of the skin is somewhat sensitive to radiation and therefore of concern in a lightly shielded spacesuit in an intense and low-energy environment.

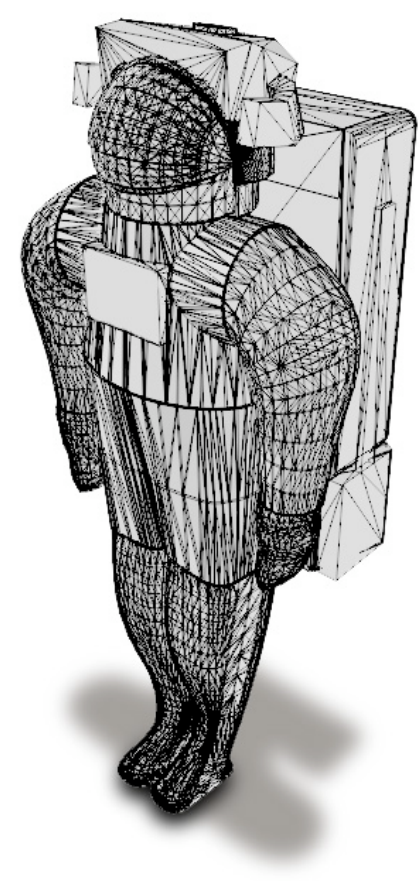

Fig. 18 Finite element model of the Shuttle Spacesuit

Table 9. Material lay-up of the spacesuit fabric and water filled tube $e^{5,21}$.

\begin{tabular}{|l|l|}
\hline Material & $\begin{array}{l}\text { Areal density, } \\
\mathrm{g} / \mathrm{cm}^{2}\end{array}$ \\
\hline Orthofabric-Teflon/Nomex/Kevlar & 0.049 \\
Reinforced Aluminized Mylar & 0.014 \\
Neoprene Coated Ripstop & 0.028 \\
Dacron® Polyester & 0.021 \\
Urethane Coated nylon Ripstop & 0.014 \\
Nylon/Spandex/water/ethylvinylacetate & 0.154 \\
\hline
\end{tabular}

The material lay-up (Fig. 19) for the fabric including the inner LCVG is given in Table 9. The outer fabric layer, the Thermal Micrometeroid Garment (TMG) is composed of the OrthoFabric, five layers of Reinforced Aluminized Mylar for thermal insulation and Neoprene Coated Nylon Ripstop. Below the TMG is the Dacron $\AA$ pressure restraint. This is followed by the Urethane Coated Nylon (pressure bladder) and the LCVG of a multifilament Nylon/Spandex knit which contains, the ethylvinylacetate tubes filled with water.

In past calculations (Kosmo et al. 1989) 22 , the materials in Table 9 were converted into equivalent amounts of 
aluminum by scaling with the ratio of range of a $50 \mathrm{MeV}$ proton in aluminum to the range in the specific material and calculations made for penetration in the equivalent aluminum. There are three concerns with this approach:

1) the equivalent aluminum scale factor depends on the proton energy and the assumed $50 \mathrm{MeV}$ is not accurate for estimation for minimum penetrating particles; 2) the water filled tubes cover less than 40 percent of the surface area and the homogenization with the Spandex over-estimates the fabric shielding (with homogenized tube) or protection properties over $60+$ percent of the area; and 3) many components of the fabric lay-up are inhomogeneous structures and may not be well represented by an average areal density. We will discuss experiments to study these effects in the next section.

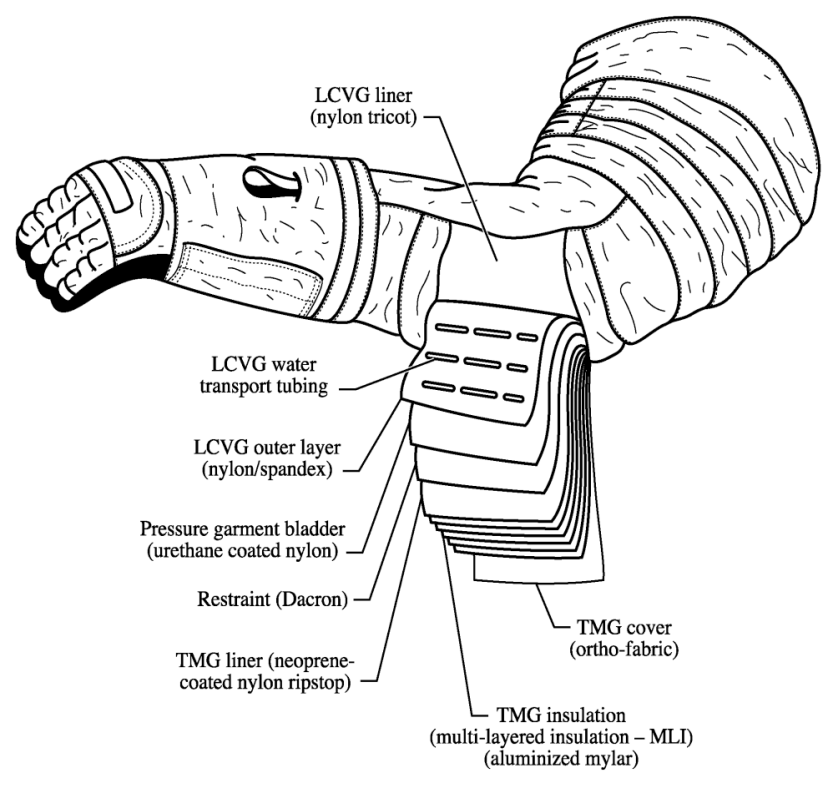

Fig. 19. Cross section of material lay-up.

Table 10 lists each component along with its modeled composition and mass properties. When the CAD model mass is compared to the true mass of the suit, the PLSS and the EVVA mass estimates are close. For the space suit assembly (SSA) itself, the values are considerably lower. This is believed to be due to the fact that the disconnects for the gloves, HUT, and arm assembly aren't modeled due to the small solid angle they possess. (Future improvements on the CAD model will incorporate these disconnects.)

The surest way to represent the actual fabric/tube transmission properties is to remove these defects by representing the water filled tube geometry specifically, transporting through actual material layers and performing penetration tests to validate models of the inhomogeneities within the remaining fabric (Wilson et al. 2001) ${ }^{23}$. These tasks are performed in the present study and the fabric transmission properties are represented as an analytical model with good agreement with low-energy proton transmission testing. The improved understanding of the fabric transmission properties will allow redesign considerations to improve the spacesuit radiation safety. The basic penetration test is given in Fig. 20. The test is in principle quite simple; a low-energy proton beam is incident from the left on a swatch of the spacesuit and water filled tubes as shown. The arrangement of the experimental setup is shown in Fig. 21 as used in the past testing. A reasonably uniform beam of approximately $34.5 \mathrm{MeV}$ protons enters the Lexan collimator from the left and is monitored by a $3 \mathrm{~mm}$ thick silicon detector $(\mathrm{d} 3 \mathrm{~mm} 1)$. The transmitted spectrum through $\mathrm{d} 3 \mathrm{~mm} 1$ was measured in a "target out" test. The monitored beam passes through the target station and analyzed by a set of position sensitive detectors (PSD1X\&Y) with total remaining energy detected by the $5-\mathrm{mm}$ silicon detector (d5mm1).

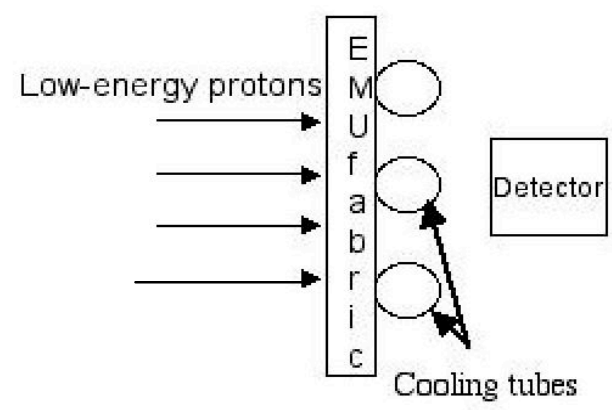

Fig. 20. Basic penetration test experimental set up.

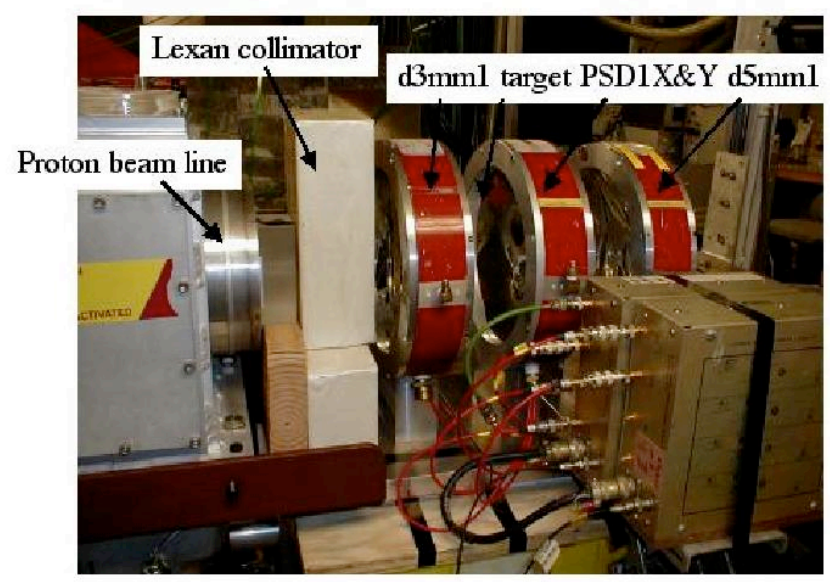

Fig. 21. Proton beamline used at the LBNL 88" cyclotron.

The beam was first analyzed without the target in place with results (no target) as the near normal distribution of particles at the far right in Fig. 22. The computational model was fit to the beam parameters before the $\mathrm{d} 3 \mathrm{~mm} 1$ and found to be of $34.54 \mathrm{MeV}$ with a standard deviation of $0.27 \mathrm{MeV}$ resulting in the 23.68 $0.46 \mathrm{MeV}$ beam 
incident on the target shown in the figure. The additional broadening of the energy spectrum is due to straggling in the $\mathrm{d} 3 \mathrm{~mm} 1$ monitor. The results of the analysis are shown in comparison to the experimental estimate of the beam properties at the target. There is an added spectral feature near $4 \mathrm{MeV}$ in the experimental data believed to be due to multiple scattering effects in the collimator.

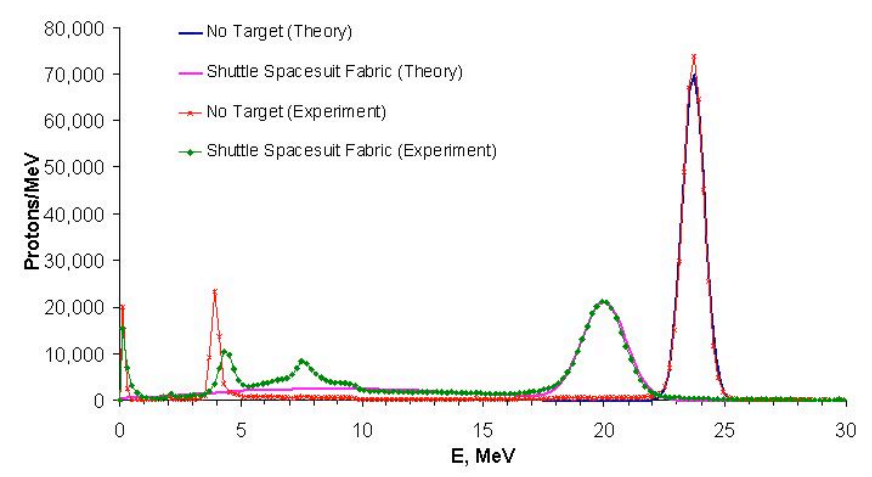

Fig. 22. Experimental and analysis results.

The beam transmitted through the target is shown also in the figure. The spectral feature at $19.94 \pm 0.967 \mathrm{MeV}$ results from the transmission through the fabric without a tube in the proton path. The increased width of this peak relative to the beam width before the target results from straggling effects in the fabric and the non-uniformity of some of the fabric components. The fabric is best fit as a normal distribution of material of mean thickness of $0.161 \pm 0.03 \mathrm{~g} / \mathrm{cm}^{2}$ of material. The mean areal density of the fabric (without the cooling tubes) is measured to be $0.185 \mathrm{~g} / \mathrm{cm}^{2}$. The height of the transmitted peak is critically dependent on the size of the tube (tube diameter is $4 \mathrm{~mm}$ ) and tube spacing (1 per centimeter). In the model, the water filled tube was assumed to be a homogeneous mixture of appropriate mass of water and ethylvinylacetate. The experiment indicates that the improved shielding properties of the water may be apparent in the data as the experimental transmitted spectral feature near $7 \mathrm{MeV}$ may be due to the inner filling of water in the tube. Hence, some added detail for the model may be required.

\section{AUGUST 1972 SPACESUIT EXPOSURES}

The Shuttle spacesuit model of the previous section is used to evaluate potential space exposures for the 4 August 1972 solar particle event (King spectrum) ${ }^{24}$. In earlier analysis, we have used the LaRC spectrum (Wilson et al. 1999) ${ }^{7}$ and the older methodology based on BFO and skin averaged thickness distributions which underestimate the average exposure by a large factor (Atwell 2006). ${ }^{25}$ Attention is given to the effects of spacesuit components on the astronaut exposures. The prior calculations mapped all materials into equivalent aluminum and the basic thickness of the fabric sections was on the order of $0.128 \mathrm{~g} / \mathrm{cm}^{2}$ according to Table 9 and equivalent to about $0.181 \mathrm{~g} / \mathrm{cm}^{2}$ of aluminum and somewhat less than the $0.3 \mathrm{~g} / \mathrm{cm}^{2}$ used in prior analysis as expected when the water filled tubes are averaged with the fabric.

Table 10: Description of CAD Modeled Spacesuit

\begin{tabular}{|c|c|c|c|c|}
\hline Component & Mass, & $\begin{array}{l}\text { Model } \\
\text { Volume, } \\
\text { cc }\end{array}$ & $\begin{array}{l}\text { Computed } \\
\text { Density, } \\
\text { g/cc }\end{array}$ & $\begin{array}{l}\text { Composition } \\
\text { (atom fraction) }\end{array}$ \\
\hline HUT & 3.52 & 2393 & 1.47 & $\begin{array}{l}.18 \mathrm{H}, .14 \mathrm{C}, .02 \mathrm{~N}, .42 \mathrm{O} \text {, } \\
.04 \mathrm{~F}, .19 \mathrm{Si}\end{array}$ \\
\hline DCM & 5.52 & 2760 & 2.00 & $\begin{array}{l}.27 \mathrm{H}, .31 \mathrm{C}, .16 \mathrm{O}, .05 \mathrm{Si} \text {, } \\
.16 \mathrm{Fe}, .05 \mathrm{Cu}\end{array}$ \\
\hline \begin{tabular}{|l|} 
Arm \\
Assembly
\end{tabular} & 1.62 & 1857 & 0.872 & $\begin{array}{l}.47 \mathrm{H}, .37 \mathrm{C}, .05 \mathrm{~N}, .11 \mathrm{O}, \\
.07 \mathrm{~F}, .003 \mathrm{Cl}\end{array}$ \\
\hline \begin{tabular}{|l} 
EVA \\
Gloves \\
\end{tabular} & 0.276 & 316 & " & (2) \\
\hline LTA & 2.88 & 3300 & $"$ & $"$ \\
\hline Legs (ea.) & 1.43 & 1641 & " & " \\
\hline Headset & 3.6 & 6984 & 0.515 & $\begin{array}{llll}.35 & \mathrm{H}, & .41 \mathrm{C}, .18 & \mathrm{O}, .053 \\
\mathrm{Si}\end{array}$ \\
\hline EVVA Shell & 1.49 & 1244 & 1.2 & $.42 \mathrm{H}, .37 \mathrm{C}, .09 \mathrm{O}$ \\
\hline \begin{tabular}{|l} 
Cen. \\
Eyeshade \\
\end{tabular} & 0.66 & 364 & 1.8 & $.66 \mathrm{O}, .33 \mathrm{Si}$ \\
\hline Sun Visor & 0.44 & 353 & 1.24 & $.41 \mathrm{H}, .50 \mathrm{C}, .07 \mathrm{O}, .02 \mathrm{~S}$ \\
\hline Prot. Visor & 0.43 & 366 & 1.2 & $.42 \mathrm{H}, .37 \mathrm{C}, .09 \mathrm{O}$ \\
\hline Helmet & 0.61 & 505 & 1.2 & $.42 \mathrm{H}, .37 \mathrm{C}, .09 \mathrm{O}$ \\
\hline $\begin{array}{l}\text { Side visors, } \\
\text { ea }\end{array}$ & 0.065 & 35 & 1.8 & $.66 \mathrm{O}, .33 \mathrm{Si}$ \\
\hline Head vent & 0.12 & 99 & 1.2 & $.42 \mathrm{H}, .37 \mathrm{C}, .09 \mathrm{O}$ \\
\hline EVC & 9.02 & 7800 & 1.16 & $\begin{array}{l}34 \mathrm{H}, .39 \mathrm{C}, .17 \mathrm{O}, .05 \mathrm{Si}, \\
.05 \mathrm{Cu}\end{array}$ \\
\hline $\begin{array}{l}\text { Warning } \\
\text { Sys. }\end{array}$ & 2.64 & 2280 & 1.16 & (a) \\
\hline Sublimator & 1.6 & 1600 & 1 & $.67 \mathrm{H}, .33 \mathrm{O}$ \\
\hline $\begin{array}{l}\text { Water Tks, } \\
\text { ea }\end{array}$ & 1.1 & 1099 & 1 & $.67 \mathrm{H}, .33 \mathrm{O}$ \\
\hline Water S\&C & 8.35 & 7220 & 1.16 & $\begin{array}{l}.27 \mathrm{H}, .31 \mathrm{C}, .16 \mathrm{O}, .05 \mathrm{Si} \text {, } \\
.16 \mathrm{Fe}, .05 \mathrm{Cu}\end{array}$ \\
\hline \begin{tabular}{|lll} 
Prim. & O \& \\
Cont & & \\
\end{tabular} & 12.8 & 11002 & 1.16 & $\begin{array}{l}24 \mathrm{H}, .28 \mathrm{C}, .14 \mathrm{O}, .04 \mathrm{Si} \text {, } \\
.22 \mathrm{Fe}, .08 \mathrm{Cu}\end{array}$ \\
\hline Sec. O Tks & 1.29 & 1643 & 0.782 & $.19 \mathrm{Cr}, .71 \mathrm{Fe}, .10 \mathrm{Ni}$ \\
\hline Back Cover & 9.8 & 7568 & 1.29 & $.42 \mathrm{H}, .37 \mathrm{C}, .09 \mathrm{O}$ \\
\hline \begin{tabular}{|l|} 
Contam. \\
Cont. \\
\end{tabular} & 2.89 & 2760 & 1.05 & $33 \mathrm{H}, .33 \mathrm{Li}, .33 \mathrm{O}$ \\
\hline Battery & 4.48 & 1200 & 3.73 & $.33 \mathrm{O}, .33 \mathrm{Zn}, .33 \mathrm{Ag}$ \\
\hline Sec O Tks & 7.61 & 23416 & 0.325 & $\begin{array}{l}.27 \mathrm{H}, .31 \mathrm{C}, .16 \mathrm{O}, .05 \mathrm{Si}, \\
.16 \mathrm{Fe}, .05 \mathrm{Cu}\end{array}$ \\
\hline
\end{tabular}

One of the tasks in design considerations is to quantify the effectiveness of the hard upper torso and backpack on exposure. The average skin exposure is $39.6 \mathrm{~Sv}$ within the full spacesuit in rough agreement with our 13 earlier estimates. With the backpack removed, the skin 
exposures increase by 21 percent to 47.9 Sv showing the value of the full suit in protecting even the skin. This could be further improved by improving the fabric shielding properties. Even more dramatic is the effect of the backpack on the red bone marrow (stem cells). The red marrow average dose is $1.72 \mathrm{~Sv}$ for the full suit but increases to $2.96 \mathrm{~Sv}$ when the backpack is removed showing a 76 percent improvement to red marrow exposure due to the backpack. In distinction, the yellow marrow (stroma cells) changes little (5 percent) as a result of the backpack. The resulting exposures to these organs are summarized in Table 11.

Table 11. Effects of backpack on the 4 August 1972 solar particle event critical organ exposures (Sv)

\begin{tabular}{|l|c|c|}
\hline Organ exposure & With backpack & Without backpack \\
\hline Skin & 39.6 & 47.9 \\
\hline Red marrow & 1.72 & 2.96 \\
\hline Yellow marrow & 5.14 & 5.42 \\
\hline
\end{tabular}

With regard to the basic spacesuit fabric/LCVG there are also advantages to consider changing in the new design. For example, the exposure as a function of thickness is shown in Fig. 23 during the 29 September 1989 solar particle event. Also indicated is the average thickness of the Shuttle spacesuit LCVG determined gravimetrically $0.284 \mathrm{~g} / \mathrm{cm}^{2}$ as reported by Kosmo and Nachtwey ${ }^{22}$ and the measured transmission test result $\left(0.161 \mathrm{~g} / \mathrm{cm}^{2}\right)$ between the water filled tubes (comprising at least 60 percent of the area). Aside from the fact that the exposures at the "as tested value" of shielding (labeled as present in Fig. 23) is over a factor of two greater than at the thickness found gravimetrically labeled Kosmo, even the types of radiation has changed dramatically from relatively high LET helium ions to lower LET protons as seen in the figure. Clearly, some advantage can be gained by homogenizing the LCVG and optimal design and placement of the upper torso and backpack elements can greatly alter the spacesuit exposures improving the survivability of the astronaut in accidental exposure. Significant gains are possible in the redesign of the spacesuit.

\section{PRELIMINARY DESIGN DEVELOPMENT}

It is clear from the above discussion that early consideration radiation shielding could greatly improve the health of the astronaut during accidental exposure. We have shown long ago that the optimal shielding is to distribute the shield mass as evenly as possible (Wilson et al 1995). ${ }^{26}$ First considerations have been to improve the effectiveness of the cooling tubes by a more uniform design with improved protection properties (Ware et al. 2003). ${ }^{27}$ The replacement of the hard upper-torso (HUT) and backpack with a soft upper-torso and reconfigured Primary Life Support System (PLSS) provides a greater opportunity to improve protection. For example, a more disperse distribution of the PLSS components could add

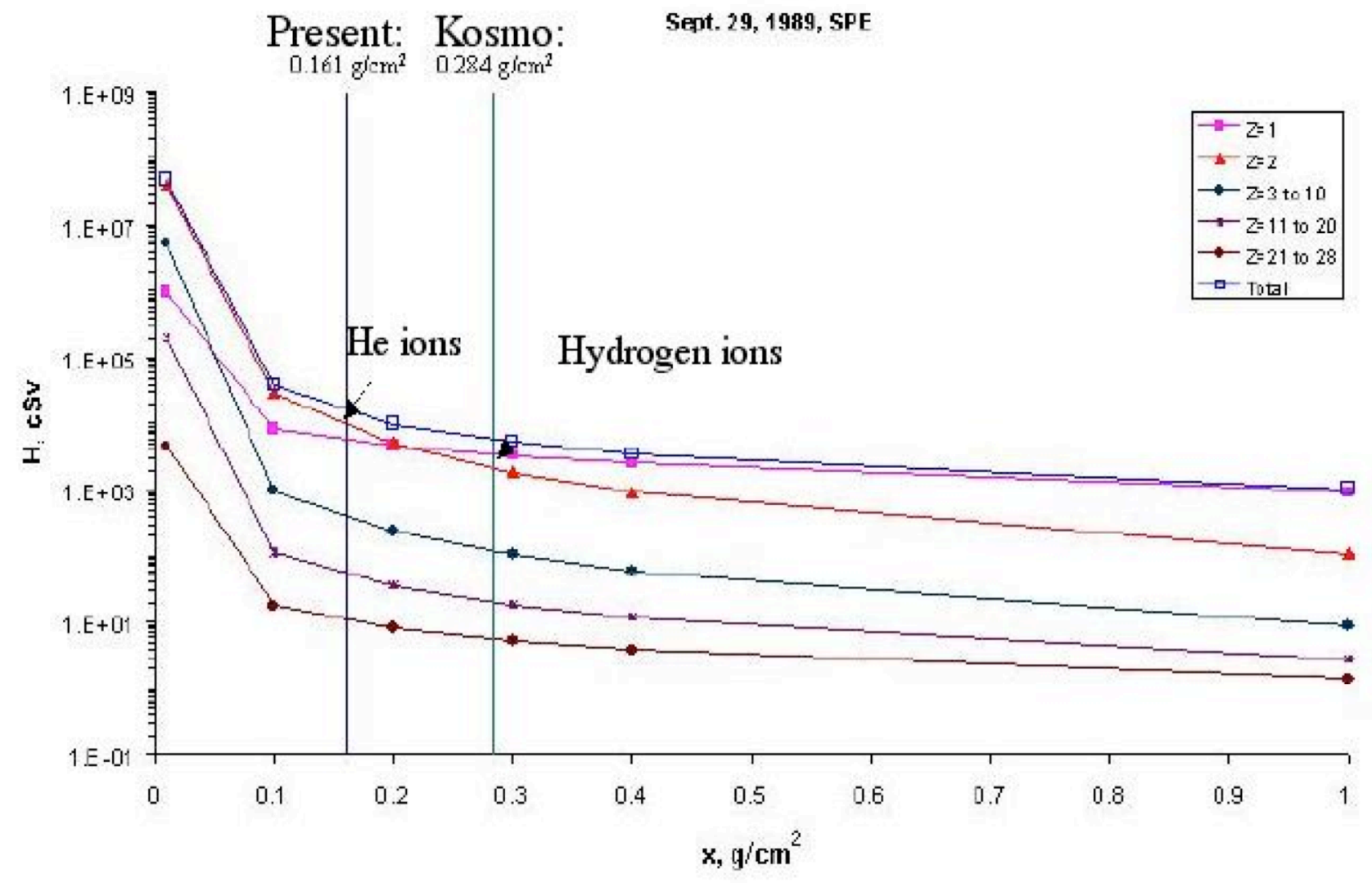

Fig. 23. Attenuation of various ions of the 29 September 1989 solar particle event in combined LCVG materials. 
to greater comfort and mobility. Clearly, configuration studies using spacesuit shield models similar to Fig. 18 could provide emphasis to useful design changes.

In a previous study (Ware et al. 2003), ${ }^{27}$ we evaluated the radiation protection characteristics of some proposed new spacesuit materials. Fifteen test target combinations of current and experimental spacesuit materials were exposed to a low energy proton beam at Lawrence Berkeley National Laboratory (LBNL). Each target combination contained all of the necessary spacesuit layers; i.e. TMG, restrain/bladder or HUT fiberglass, and LCVG. Some of these target combinations modeled accurately the current Shuttle spacesuit used as a baseline design. In others, new materials were substituted for one or more layers of the target combination. The new materials included low-density linear polyethylene (LLPE) films substituted for the aluminized mylar in the TMG and the urethane coated nylon bladder currently in the suit. Spectra ${ }^{\circledR}$, a high-density polyethylene fiber in knit and woven fabrics, was substituted for the LCVG nylon/Spandex net and nylon liner and the Dacron ${ }^{\circledR}$ restraint. Finally, a new water jacket concept, which more evenly distributes the water, was substituted for the LCVG. These materials were chosen because they are less porous than current materials and/or contain higher concentrations of hydrogen. The results from this study show that the water jacket and LLPE film in place of reinforced aluminized mylar in the TMG do provide more radiation protection than the current materials. Further analysis of these data is required to develop a baseline model of the HUT. This study begins to provide the models and data necessary to redesign the SSA for improved radiation protection.

Incorporation of material changes in the SSA must be carefully considered with respect to SSA safety and performance. The introduction of a water jacket, which has the most-clear advantage to improving radiation shielding, may be disadvantageous to other SSA design goals. Although the current SSA LCVG has water tubes, they are much less dense and carry less water volume than the proposed water jacket. Increased water volume in the SSA has several negative impacts to SSA performance. The increased water adds mass to the SSA. Mass is costly, it decreases SSA mobility, and it contributes to crewmember fatigue. In addition, water leakage in the SSA is a safety concern and increased water volume increases the risks associated with leakage. In designing advanced spacesuit assemblies, it will be necessary to determine where increased radiation protection has the greatest effect and to minimize the negative impacts to performance. For instance, increasing the density of water tubes or using a water jacket in the HUT portion of the SSA will have less of an impact to mobility since this area is fairly rigid and static. The current LCVG tubing is used to circulate water for crewmember cooling. Addition of water to the SSA for radiation protection might be included in a garment or system other than the cooling system which could lower the risks associated with leakage.

Incorporation of polyethylene film layers in the SSA is a reasonable goal for redesign efforts. Polyethylene material is already accepted in the SSA with respect to material compatibility. As used in the TMG to replace reinforced aluminized mylar, the polyethylene would require a reflective coating for thermal protection. Thermal protection as well as micrometeoroid protection must be maintained and verified with a change to the TMG material lay-up.

\section{CONCLUSION}

As NASA approaches a new era of space exploration, the design of the Shuttle spacesuit for use in free space provides an inappropriate design for use on the Moon and Mars. As a new design evolves, it is appropriate to consider allowing radiation-shielding factors as part of the design process. This makes sense for two reasons, EVA will be a major activity in exploration of the lunar and Martian surfaces and there is a greater potential of exposure to a solar particle event without the protection provided by the Earth's protective magnetic field. Methods for involving radiation protection into the design process are presented in the present paper providing design optimization and a testing protocol for new materials.

\section{REFERENCES}

1. NCRP: Radiation Protection Guidance for Activities in Low-Earth Orbit. NCRP Report No. 132, 2000.

2. NCRP: Operational Radiation Safety Program for Astronauts in Low-Earth Orbit: A basic Framework. NCRP Report No. 142, 2002.

3. Wilson, J.W., Kim, M.-H. Y., De Angelis, G., Cucinotta, F. A.. Yoshizawa, N., Badavi, F.F. Implementation of Gy-Eq for Deterministic Effects Limitation in Shield Design. J. Radiat. Res. 43: S103-S106; 2002.

4. Simonsen, L.C., Cucinotta, F.A., Atwell, W., Nealy, J.E. Temporal Analysis of the October 1989 Proton Flare using Computerized Anatomical Models. Radiation Research 133, 1993, pp. 1-11.

5. Ross, A.J., Webbon, Bruce, Wilson, J.W., Simonsen, L.C. Spacesuits. NASA Conference Publication 3360, December 1997.

6. Kim, Myung-Hee Y., Wilson, John W., Simonsen, Lisa C., Cucinotta, Francis A., Atwell, William, Badavi, Francis F., Miller, J. Contribution of High Charge and Energy (HZE) lons During Solar-Particle Event of September 29, 1989 NASA TP-209320, 1999.

7. Wilson, J.W., Cucinotta, F.A., Shinn, J.L., Simonsen, L.C., Dubey, R.R., Jordan, W.R., Jones, T.D., Chang, C.K., Kim, M.Y., Shielding from solar particle 
events in deep space. Radiat. Meas. 30(3): 361-382; 1999.

8. Reames, D. Solar energetic particles: Is there time to hide?, Radiat. Meas. 30(3): 297-308; 1999.

9. Neal, J.S., Townsend, L.W., Multiple Solar Particle Event Dose Time Profile Predictions Using Bayesian Inference. Radiation Protection Dosimetry in press.

10. Xapsos, M.A., Summers, G.P., Barth, J.L., Stassinopoulos, E.G., Burke, E.A. Probability model for worst case Solar Particle Event fluences. IEEE Trans. Nucl. Sci. 46: 1481-1485; 1999.

11. Langham, W.R., ed.: Radiobiological Factors in Manned Space Flight. National Academy of Sciences, Publ. 1487, 1967.

12. Wilson, J.W., Townsend, L.W., Nealy, J.E., Chun, S.Y., Hong, B.S., Buck, W.W., Lamkin, S.L., Ganapol, B.D., Khan, F., Cucinotta, F.A. BRYNTRN: A Baryon Transport Model. NASA TP-2887, 1989.

13. Feynman, J., Armstrong, T.P., Dao-Gibner, L., Silverman, S. New Interplanetary Proton Fluence Model. J. Spacecraft, 27:403-410; 1990.

14. Jones, T.D., Morris, M.D., Young, R.W., Dose-rate RBE factors for photons: Hematopoietic syndrome in humans vs. stromal cell cytopenia. Health Phys. 67: 495-508; 1994

15. Jones, T. D., Hematopoietic syndrome in man modeled from mammalian lethality. Health Physics 41:83-103, 1981

16. UNSCEAR, Sources, effects and risks of ionizing radiation. United Nations, New York, 1988, pp 613647.

17. Levin, S.G., Young, R. W., Stohler, R. L., Estimates of median lethal radiation dose computed from data on occupants and architecture of two reinforced concrete structures in Nagasaki, Japan. Health Phys 63:522-531, 1992

18. Morris, M. D., Jones, T. D., Young. R. W., A cell kinetics model of radiation-induced myelopoiesis: Rate coefficient estimates for mouse, rat, sheep, swine, and burro irradiated by photons. Radiat Res 135:320-331, 1993.
19. Morris, M. D., Jones. T. D. A comparison of doseresponse models for death from hematological depression in different species. Int $J$ Radiat Biol 53:439-456, 1988.

20. Jones, T. D., Morris, M. D., Young, R. W., Kehlet, R. A. Neutron RBEs for Cytopenia and Repopulation of Stromal and Hematopoietic Stem Cells: Mathematical Models of Marrow Cell Kinetics. Health Phys. 72:530-543; 1997.

21. Anderson, B.A., Nealy, J.E., Wilson, J.W., Simonsen, L.C. CAD Model of Astronaut Radiation Exposures During EVA: Nominal and Extreme Scenarios. SAE 01ICES-2363, 2001.

22. Kosmo J.J., Nachtwey D.S., Hardy A. JSC/CTSDSS-241, 1-24-1989.

23. Wilson, J.W.; Tweed, J.; Zeitlin, C.; Anderson, B.M.; Cucinotta, F.A.; Ware, J.; Persans, A.E. Shuttle Spacesuit: Fabric/LCVG Model Validation. SAE/ICES 2001-01-2372; 2001.

24. King, J.H. Solar Proton Fluences for 1977-1983 Space Missions. J. Spacecr. \& Rockets 11(6): 401408; 1974.

25. Atwell, Wm. Personal communication, 2006.

26. Wilson, J.W., et al., Variations in Astronaut Radiation Exposure Due to Anisotropic Shield Distribution. Health Phys. 69, 34-45, 1995.

27. Ware, J., Ferl, J., Wilson, J.W., Clowdsley, M.S., de Angelis, G., Tweed, J., Zeitlin, C.J. Test results of improved spacesuit shielding components. SAE 03ICES-80. 2003.

\section{CONTACT}

J.W. Wilson received his $\mathrm{PhD}$ from the College of William and Mary in 1975.

Email: john.w.wilson@nasa.gov. See Verified by a Netscape Security Partner:

http://csmb.larc.nasa.gov/csmbexternal/Personnel/Wilso n/wilsonbio.html 